\title{
Factors affecting fluid flow in strike-slip fault systems: coupled deformation and fluid flow modelling with application to the western Mount Isa Inlier, Australia
}

\author{
A. FORD, T.G. BLENKINSOP AND J.G. MCLELLAN \\ Economic Geology Research Unit, Predictive Mineral Discovery Cooperative Research Centre, James Cook University, \\ Townsville, Qld, Australia
}

\begin{abstract}
Deformation and focused fluid flow within a mineralized system are critical in the genesis of hydrothermal ore deposits. Dilation and integrated fluid flux due to coupled deformation and fluid flow in simple strike-slip fault geometries were examined using finite difference analysis in three dimensions. A series of generic fault bend and fault jog geometries consistent with those seen in the western Mount Isa Inlier were modelled in order to understand how fault geometry parameters influence the dilation and integrated fluid flux. Fault dip, fault width, bend/jog angle, and length were varied, and a cross-cutting fault and contrasting rock types were included. The results demonstrate that low fault dips, the presence of contrasts in rock type, and wide faults produce highest dilation and integrated fluid flux values. Increasing fault bend lengths and angles increases dilation and integrated fluid flux, but increasing fault jog length or angle has the opposite effect. There is minimal difference between the outputs from the releasing and restraining fault bend and jog geometries. Model characteristics producing greater fluid flows and/or gradients can be used in a predictive capacity in order to focus exploration on regions with more favorable fault geometries, provided that the mineralized rocks had Mohr-Coulomb rheologies similar to the ones used in the models.
\end{abstract}

Key words: deformation, FLAC ${ }^{3 D}$, fluid flow, Mount Isa, numerical modelling, strike-slip faults

Received 5 December 2007; accepted 8 September 2008

Corresponding author: Arianne Ford, Centre for Exploration Targeting, University of Western Australia, Crawley, WA 6009, Australia.

Email: arianne.ford@uwa.edu.au. Tel: +61 86488 5805. Fax: +61 864881178.

Geofluids (2009) 9, 2-23

\section{INTRODUCTION}

Deformation and fluid flow are critical factors for many forms of hydrothermal mineralization (Ord 1990; Laing 1998; Cox 1999, 2005; Garven et al. 2001; Oliver et al. 2001; Tripp \& Vearncombe 2004; Bonson et al. 2007). Coupling of these factors in numerical models can lead to new insights into different mineralizing systems, with implications for ore genesis and potential identification of exploration targets (Gow et al. 2002; Zhang et al. 2003; McLellan et al. 2004; Oliver et al. 2006; Rawling et al. 2006; Schaubs et al. 2006). Faults (and especially fault bends, jogs, and intersections) and contacts between different lithostratigraphic units can create an environment conducive to increased fluid flow in the system (Craw 2000;
Allibone et al. 2002a; Cox 2005; Hodkiewicz et al. 2005; Ford \& Blenkinsop 2008).

Both strike-slip and dip-slip faulting are commonly investigated in two-dimensional modelling (Zhang \& Sanderson 1996; Chester \& Fletcher 1997; Sanderson \& Zhang 1999; Chester \& Chester 2000; Oliver et al. 2001; Zhang et al. 2003; McLellan et al. 2004; McLellan \& Oliver 2007), with three-dimensional modelling experiments generally focusing on dip-slip faulting (Egan et al. 1999; Gow et al. 2002; Sorjonen-Ward et al. 2002; Rawling et al. 2006). However, two-dimensional models of strikeslip faulting do not necessarily provide a good representation of fluid flow during deformation. Brankman \& Aydin (2004) took steps to address this issue by modelling a constant overstep fault jog geometry in strike-slip deformation 
using a boundary element code to examine the effect of variation of the stress regime and to reinterpret the deformation history in three dimensions. No published example has been found of a numerical modelling study of threedimensional strike-slip fault systems examining the effect of variable fault geometry.

The aims of this paper are to systematically investigate and quantify the effect of different fault bend and jog geometries and rock types on the volumetric strain and fluid flow outputs from three-dimensional coupled deformation and fluid flow models of strike-slip fault systems. These results may assist in mineral exploration.

The Western Succession of the Mount Isa Inlier hosts some of the largest copper deposits within the region, such as Mount Isa, Mammoth, and Esperanza, which are associated with regional steeply dipping $\mathrm{N}-\mathrm{S}$ striking structures (Van Dijk 1991; Drummond et al. 1998). Model geometries in this study are characteristic of Mount Isa Inlier geology at the time of copper mineralization, and may also serve as a generic model for the exploration of fluid flow in strike-slip fault systems with similar material properties.

\section{REGIONAL GEOLOGY}

The western Mount Isa Inlier can be separated from the remainder of the outcropping Proterozoic province based on the stratigraphy and seismic refraction data, which shows that a terrain boundary may exist near the Pilgrim Fault (Blake \& Stewart 1992; McDonald et al. 1997). To the west of this line, the stratigraphy is referred to as the Western Succession. The Western Succession is dominated by N-S to NE striking faults (Scott \& Taylor 1982; Bell et al. 1988; Nijman et al. 1992; Queensland Department of Mines and Energy, Taylor Wall and Associates, SRK Pty Ltd and ESRI Australia 2000). These structures were formed and reactivated during the major $\mathrm{D}_{2}$ E-W shortening event (approximately $1590 \mathrm{Ma}$ ) (Bell et al. 1988; Laing 1998). Further, possibly strike-slip, reactivation of these faults occurred during $\mathrm{D}_{3}$ (approximately $1550 \mathrm{Ma}$ ), also an approximately E-W shortening event, and perhaps as late as the Cambrian and Ordovician (Feltrin et al. 2003; Mark et al. 2004). Seismic profiles indicate that the majority of faults in the region are steeply dipping (Drummond et al. 1998; MacCready et al. 2006).

Major fault zones in the Western Succession include the Western Border, Mount Isa, and Mount Gordon fault zones, which are steeply dipping $\mathrm{N}-\mathrm{S}$ to NNE striking structures (Van Dijk 1991; Drummond et al. 1998). Splays off each of these major structures have variable strikes. Previous studies have suggested a spatial relationship between major copper ore bodies and fault bends and fault intersections within the Mount Isa Inlier (Oliver et al. 2001; Ford \& Blenkinsop 2007; McLellan \& Oliver 2007). Figure 1 illustrates a number of copper deposits in the Gunpowder region of the Western Succession proximal to fault bends, fault jogs, and fault intersections.

Copper deposits in the Western Succession are predominantly hosted by brecciated sediments adjacent to faults (Scott \& Taylor 1982; Blake et al. 1990; Van Dijk 1991). The lithostratigraphic units that host these deposits vary distinctly over the region, and the deposits are commonly proximal to major faults. For example, the Lady Annie $\mathrm{Cu}$ deposit in the Lawn Hill Platform is hosted by the McNamara Group, which is dominated by sideritic and locally carbonaceous shales, mudstones, and sandstones, and is proximal to the Western Border fault zone (Van Dijk 1991). The world-class Mount Isa copper deposit is hosted by the Urquhart Shale and sits immediately above the Eastern Creek Volcanics (metabasalts) (Wyborn 1987; Matthäi et al. 2004). The deposit lies just to the east of the Mount Isa fault zone, which has been proposed as a fluid and heat conduit in the mineralizing system (Matthäi et al. 2004). The Mammoth and Esperanza copper deposits are both located within the Mount Gordon fault zone north of Mount Isa, near Gunpowder, with Mammoth being hosted by the Myally Subgroup (quartzite, sandstone, and siltstone) and Esperanza hosted by the Esperanza Formation (dolostone and chert) (Scott \& Taylor 1982; Van Dijk 1991; Nijman et al. 1992).

\section{NUMERICAL MODELLING}

This study aimed to investigate generic controls on deformation, fluid flow, and possible mineralization based on the general Western Succession Mount Isa geology, rather than specific local controls. The effects of different fault geometries, rock types, and a combination of the two are tested in three-dimensional models to determine the most favorable variables in terms of potential for hydrothermal copper mineralization in the Western Succession. Using Fast Lagrangian Analysis of Continua in Three Dimensions (FLAC $^{3 \mathrm{D} \odot}$ ) (Itasca Consulting Group 2002), coupled deformation and fluid flow models were constructed and tested to determine which configurations had the highest mineralization potential, based on those with the highest dilation and fluid flux values. Table 1 summarizes the models tested.

A simple fault bend geometry is shown in Fig. 2 with the length of the fault bend/jog $(L)$, dip $(D)$, width of fault $(w)$, and orientation of fault bend/jog relative to north $(\theta$, positive values clockwise from north, negative values anti-clockwise) being varied in the models. Figures 3 and 4 illustrate the basic geometry of the fault jog models and intersecting fault models, respectively. The effect of parameter variation was evaluated by varying each parameter from a standard geometry in which $L=2500 \mathrm{~m}$, $\theta=-150^{\circ}, D=90^{\circ}$, and $w=50 \mathrm{~m}$. 


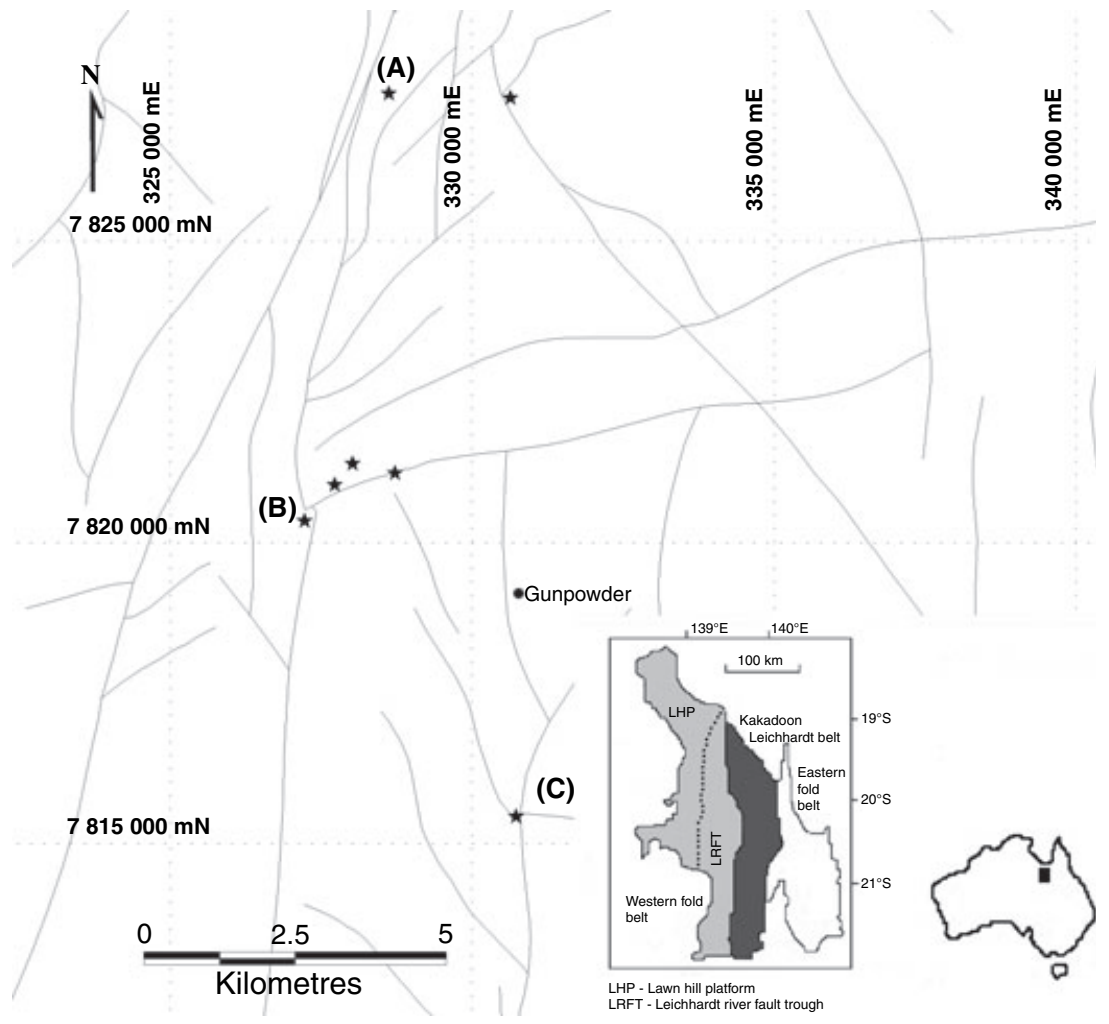

Fig. 1. Copper deposits in the Gunpowder region of the Western Succession proximal to fault bends, jogs, and intersections. Map illustrating copper deposits ( $\star$ ) in the Gunpowder region of the Western Succession of the Mount Isa Inlier proximal to (A) a fault bend, (B) a fault jog (with a cross-cutting fault), and (C) a fault intersection. Faults are interpreted from the Northwest Queensland Mineral Province Report (Queensland Department of Mines and Energy, Taylor Wall and Associates, SRK Pty Ltd and ESRI Australia 2000). Copper deposit locations extracted from the Queensland Mineral Occurrence Database (Queensland Department of Natural Resources and Mines 2005). Inset illustrates location of the three tectonic divisions of the Mount Isa Inlier with the Western Succession comprising of the Western Fold Belt and the Kalkadoon-Leichhardt Belt (Blake \& Stewart 1992; McDonald et al. 1997).

\section{Constitutive relationships and lithological properties}

A Mohr-Coulomb constitutive model was used, which is appropriate for representing the elastic-plastic deformation in the mid- to upper crust (cf. Oliver et al. 2001; Strayer et al. 2001; Zhang et al. 2003; Brankman \& Aydin 2004; Rawling et al. 2006). Fluid flow is expressed by Darcy's law for flow in a porous media (Oliver et al. 2001, 2006; McLellan et al. 2004). Gessner et al. (2006) discuss shearhosted $\mathrm{Cu}$ mineralization at Mount Isa and use the MohrCoulomb constitutive model to model the Mount Isa $\mathrm{Cu}$ deposit in FLAC ${ }^{3 \mathrm{D}}$, corroborating the appropriateness of this constitutive model for the study.

Vermeer \& de Borst (1984) summarize the Mohr-Coulomb constitutive model by defining the elastic moduli, yield functions for shear and tensile failure, and the corresponding functions for plastic strain related to yielding. Cohesion, friction angle and tensile strength can be used to define the yield functions. Materials will initially deform elastically up to a yield point, at which point the material will deform plastically. The plastic deformation is associated with shear or tensile failure, which leads to dilatancy in the material. Fluid flux in a system defined by Darcy's law is governed by the conductivity and hydraulic head $(H)$, which is related to elevation above a given point $(z)$, acceleration due to gravity $(g)$, pore fluid pressure $(P)$ and the fluid density $(\rho)$ such that
$H=z+P / \rho g$

The equation for Darcy's law is given by

$V_{\mathrm{f}}-V_{\mathrm{s}}= \pm k_{i j} \frac{\gamma_{\mathrm{f}}}{\eta_{\mathrm{f}}}\left(\frac{\partial H}{\partial x_{j}}\right)$

where $H$ is the previously defined hydraulic head, $V_{\mathrm{f}}$ is the fluid velocity $\left(\mathrm{m} \mathrm{s}^{-1}\right), V_{\mathrm{s}}$ is the velocity of the solid materials $\left(\mathrm{m} \mathrm{s}^{-1}\right), k_{i j}$ is the permeability tensor $\left(\mathrm{m}^{2}\right), \gamma_{\mathrm{f}}$ is the specific weight of the fluid in the pore space $\left(\mathrm{kg} \mathrm{m}^{-2} \mathrm{~s}^{-2}\right), \eta_{\mathrm{f}}$ is the fluid viscosity $\left(\mathrm{kg} \mathrm{m}^{-1} \mathrm{~s}^{-1}\right)$ and $x_{j}$ represents the component $(j)$ of the vector $x$ in a Cartesian system of reference axes (cf. Wang 2000; McLellan et al. 2004).

During plastic deformation, high strain can cause positive dilation, which is governed by the dilation angle $\psi$ where:

$\sin \psi=\varepsilon_{v}^{\mathrm{p}} / \gamma^{\mathrm{P}}$

and $\varepsilon_{v}^{\mathrm{P}}$ is the plastic volumetric strain rate and $\gamma^{\mathrm{P}}$ is the plastic shear strain rate (McLellan et al. 2004).

This dilation (or contraction) can cause a change in pore pressure, which in turn affects the hydraulic head, and thus the fluid flux within the system. The dilation also leads to changes in the effective stress, thus affecting plastic deformation. This feedback loop between the deformation and fluid flow continues in a coupled manner. More 
Table 1 Summary of model configurations tested.

\begin{tabular}{|c|c|c|c|c|c|c|c|c|c|}
\hline Model no. & Bend/jog & Rock type(s) & $\theta$ & $L(\mathrm{~m})$ & $D$ & $W(\mathrm{~m})$ & X-cut & Dilation ratio & IFF ratio \\
\hline 1 & Bend & ECV & $-175^{\circ}$ & 2500 & $90^{\circ}$ & 50 & $\mathrm{~N}$ & -0.00046 & 804.44 \\
\hline $2^{*}$ & Bend & ECV & $-165^{\circ}$ & 2500 & $90^{\circ}$ & 50 & $\mathrm{~N}$ & * & * \\
\hline 3 & Bend & ECV & $-150^{\circ}$ & 2500 & $90^{\circ}$ & 50 & $\mathrm{~N}$ & -0.00048 & 807.70 \\
\hline 4 & Bend & ECV & $-135^{\circ}$ & 2500 & $90^{\circ}$ & 50 & $\mathrm{~N}$ & -0.00052 & 793.89 \\
\hline 5 & Bend & ECV & $175^{\circ}$ & 2500 & $90^{\circ}$ & 50 & $\mathrm{~N}$ & -0.00047 & 803.53 \\
\hline 6 & Bend & ECV & $165^{\circ}$ & 2500 & $90^{\circ}$ & 50 & $\mathrm{~N}$ & -0.00049 & 800.67 \\
\hline 7 & Bend & ECV & $150^{\circ}$ & 2500 & $90^{\circ}$ & 50 & $\mathrm{~N}$ & -0.00052 & 793.67 \\
\hline 8 & Bend & ECV & $135^{\circ}$ & 2500 & $90^{\circ}$ & 50 & $\mathrm{~N}$ & -0.00058 & 782.39 \\
\hline 9 & Bend & ECV & $-150^{\circ}$ & 2500 & $90^{\circ}$ & 25 & $\mathrm{~N}$ & -0.00032 & 997.17 \\
\hline 10 & Bend & ECV & $-150^{\circ}$ & 2500 & $90^{\circ}$ & 100 & $\mathrm{~N}$ & -0.00075 & 688.30 \\
\hline 11 & Bend & ECV & $-150^{\circ}$ & 500 & $90^{\circ}$ & 50 & $\mathrm{~N}$ & -0.00048 & 779.14 \\
\hline 12 & Bend & ECV & $-150^{\circ}$ & 1000 & $90^{\circ}$ & 50 & $\mathrm{~N}$ & -0.00048 & 783.26 \\
\hline 13 & Bend & ECV & $-150^{\circ}$ & 5000 & $90^{\circ}$ & 50 & $\mathrm{~N}$ & -0.00054 & 819.67 \\
\hline 14 & Bend & ECV & $-150^{\circ}$ & 2500 & $-85^{\circ}$ & 50 & $\mathrm{~N}$ & -0.00051 & 823.80 \\
\hline 15 & Bend & ECV & $-150^{\circ}$ & 2500 & $85^{\circ}$ & 50 & $\mathrm{~N}$ & -0.00051 & 823.76 \\
\hline 16 & Bend & ECV & $-150^{\circ}$ & 2500 & $-45^{\circ}$ & 50 & $\mathrm{~N}$ & -0.01041 & 1278.8 \\
\hline 17 & Bend & ECV & $-150^{\circ}$ & 2500 & $45^{\circ}$ & 50 & $\mathrm{~N}$ & -0.01041 & 1278.8 \\
\hline 18 & Bend & ECV & $-150^{\circ}$ & 2500 & $90^{\circ}$ & 50 & $Y$ & -0.00062 & 818.54 \\
\hline 19 & Jog & ECV & $-175^{\circ}$ & 2500 & $90^{\circ}$ & 50 & $\mathrm{~N}$ & -0.00044 & 872.78 \\
\hline 20 & Jog & ECV & $-165^{\circ}$ & 2500 & $90^{\circ}$ & 50 & $\mathrm{~N}$ & -0.00044 & 865.79 \\
\hline 21 & Jog & ECV & $-150^{\circ}$ & 2500 & $90^{\circ}$ & 50 & $\mathrm{~N}$ & -0.00044 & 860.70 \\
\hline 22 & Jog & ECV & $-135^{\circ}$ & 2500 & $90^{\circ}$ & 50 & $\mathrm{~N}$ & -0.00044 & 851.48 \\
\hline 23 & Jog & ECV & $175^{\circ}$ & 2500 & $90^{\circ}$ & 50 & $\mathrm{~N}$ & -0.00044 & 865.31 \\
\hline 24 & Jog & ECV & $165^{\circ}$ & 2500 & $90^{\circ}$ & 50 & $\mathrm{~N}$ & -0.00044 & 857.53 \\
\hline 25 & Jog & ECV & $150^{\circ}$ & 2500 & $90^{\circ}$ & 50 & $\mathrm{~N}$ & -0.00044 & 855.55 \\
\hline 26 & Jog & ECV & $135^{\circ}$ & 2500 & $90^{\circ}$ & 50 & $\mathrm{~N}$ & -0.00044 & 855.76 \\
\hline 27 & Jog & ECV & $-150^{\circ}$ & 2500 & $90^{\circ}$ & 25 & $\mathrm{~N}$ & -0.00030 & 1093.2 \\
\hline 28 & Jog & ECV & $-150^{\circ}$ & 2500 & $90^{\circ}$ & 100 & $\mathrm{~N}$ & -0.00065 & 738.08 \\
\hline $29^{*}$ & Jog & ECV & $-150^{\circ}$ & 500 & $90^{\circ}$ & 50 & $\mathrm{~N}$ & $*$ & * \\
\hline 30 & Jog & ECV & $-150^{\circ}$ & 1000 & $90^{\circ}$ & 50 & $\mathrm{~N}$ & -0.00044 & 861.47 \\
\hline 31 & Jog & ECV & $-150^{\circ}$ & 5000 & $90^{\circ}$ & 50 & $\mathrm{~N}$ & -0.00043 & 897.80 \\
\hline 32 & Jog & ECV & $-150^{\circ}$ & 2500 & $-85^{\circ}$ & 50 & $\mathrm{~N}$ & -0.00046 & 871.86 \\
\hline 33 & Jog & ECV & $-150^{\circ}$ & 2500 & $85^{\circ}$ & 50 & $\mathrm{~N}$ & -0.00046 & 872.01 \\
\hline 34 & Jog & $\mathrm{ECV}$ & $-150^{\circ}$ & 2500 & $-45^{\circ}$ & 50 & $\mathrm{~N}$ & -0.00543 & 1000.3 \\
\hline 35 & Jog & ECV & $-150^{\circ}$ & 2500 & $45^{\circ}$ & 50 & $\mathrm{~N}$ & -0.00543 & 1000.6 \\
\hline 36 & Jog & ECV & $-150^{\circ}$ & 2500 & $90^{\circ}$ & 50 & Y & -0.00043 & 893.43 \\
\hline 37 & Bend & $\mathrm{ECV} / \mathrm{Syb}$ & $-150^{\circ}$ & 2500 & $90^{\circ}$ & 0 & $\mathrm{~N}$ & -0.00085 & 53.794 \\
\hline 38 & Bend & ECV/Syb/Urq & $-150^{\circ}$ & 2500 & $90^{\circ}$ & 0 & $\mathrm{~N}$ & -0.00076 & 64.057 \\
\hline 39 & Bend & ECV/MSG & $-150^{\circ}$ & 2500 & $90^{\circ}$ & 50 & $\mathrm{~N}$ & -0.00057 & 3504.7 \\
\hline 40 & Bend & $\mathrm{ECV} / \mathrm{Syb}$ & $-150^{\circ}$ & 2500 & $90^{\circ}$ & 50 & $\mathrm{~N}$ & -0.00055 & 11326 \\
\hline 41 & Bend & $\mathrm{ECV} / \mathrm{MSG}$ & $-150^{\circ}$ & 2500 & $90^{\circ}$ & 50 & Y & -0.00194 & 9309.5 \\
\hline 42 & Bend & $\mathrm{ECV} / \mathrm{MSG} / \mathrm{Urq}$ & $-150^{\circ}$ & 2500 & $90^{\circ}$ & 50 & $\mathrm{Y}$ & -0.00066 & 6772.1 \\
\hline 43 & Jog & $\mathrm{ECV} / \mathrm{MSG} / \mathrm{Urq}$ & $-150^{\circ}$ & 2500 & $90^{\circ}$ & 50 & Y & -0.00065 & 7818.9 \\
\hline 44 & Jog & ECV/MSG & $-150^{\circ}$ & 2500 & $90^{\circ}$ & 50 & Y & -0.00123 & 8440.1 \\
\hline
\end{tabular}

ECV, Eastern Creek Volcanics (metabasalts); MSG, Myally Subgroup (quartzite); Syb, Sybella Granite; Urq, Urquhart Shale.

*Note: Model 2 and Model 29 failed to run to $10 \%$ shortening.

comprehensive explanations of the Mohr-Coulomb constitutive model, Darcy's law, and the coupling of deformation and fluid flow are provided by Vermeer \& de Borst (1984), Ord \& Oliver (1997), Oliver et al. (2001) and McLellan et al. (2004).

The strike of the main faults in the models is $\mathrm{N}-\mathrm{S}$, similar to the orientations of the Western Border fault zone $(\mathrm{N}-\mathrm{S})$, Mount Isa fault zone $(\mathrm{N}-\mathrm{S})$ and the Mount Gordon fault zone (NNE), which are proximal to the most significant copper ore bodies in the Western Succession. Additional geometries considered include an E-W striking fault through the middle of the model, similar to a set of faults in this general orientation in the Western Succession (e.g. Fig. 1). Many of these E-W trending faults have been interpreted as half-graben structures and have been related to the copper mineralization in the region (cf. Gibson \& Hitchman 2005). The dimensions of all models were $\mathrm{E}-\mathrm{W}=10 \mathrm{~km}, \mathrm{~N}-\mathrm{S}=8 \mathrm{~km}$ and depth $=5 \mathrm{~km}$.

Properties of the surrounding host rock were chosen to be representative of the Eastern Creek Volcanics, as this has been suggested as the source of copper at Mount Isa,

(c) 2008 The Authors

Journal compilation @ 2008 Blackwell Publishing Ltd, Geofluids, 9, 2-23 

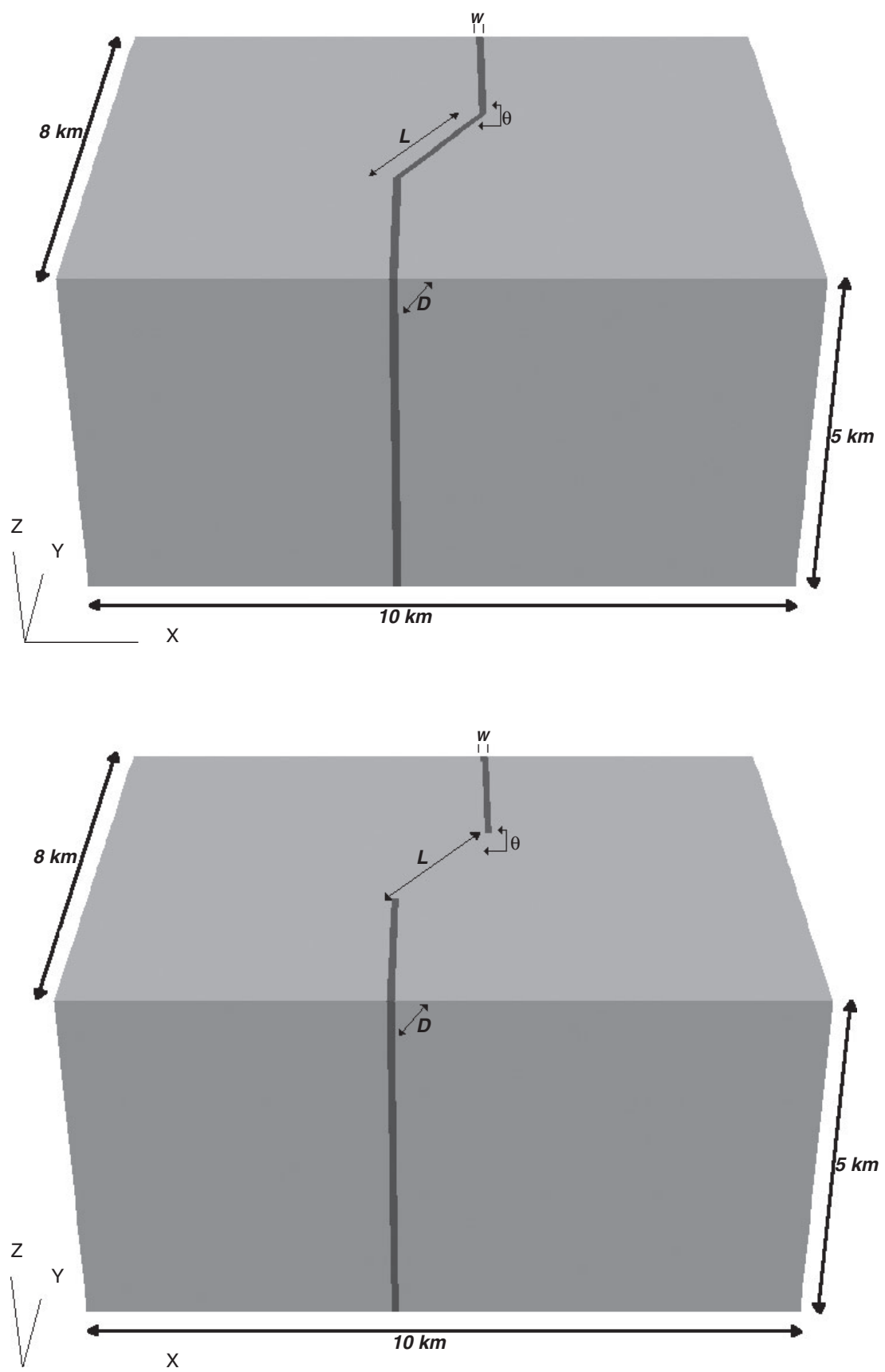

Fig. 2. Fault bend geometry (Model 3). Parameters varied during $\mathrm{FLAC}^{3 \mathrm{D}}$ modelling, also shown in Figs 3 and 4 , are length of fault bend $(L)$, dip $(D)$, orientation of fault bend/jog $(\theta=\varphi)$, and width of fault $(w)$. Direction of shortening is $112.5^{\circ}$.
Fig. 3. Fault jog geometry (Model 21). See caption to Fig. 2 for definition of parameters.
Mammoth and Esperanza (Scott \& Taylor 1982; Wyborn 1987; Heinrich et al. 1995; Matthäi et al. 2004). Other rock properties (Table 2) were assigned to be representative of the Mount Isa and Gunpowder regions, e.g. the Sybella Granite unit, an Urquhart Shale unit, and/or a Myally Subgroup (quartzite) unit. The top of all the models represents a depth of $5 \mathrm{~km}$, consistent with previous studies indicating that the depth of emplacement of the copper ore body at Mount Isa was between 5 and $10 \mathrm{~km}$ with an average density of $2700 \mathrm{~kg} \mathrm{~m}^{-3}$ for the overburden (Matthäi et al. 2004).

\section{Boundary conditions}

The models were initialized with a hydrostatic fluid pressure, which was then allowed to vary from hydrostatic to near lithostatic during the running of the models (cf. Oliver et al. 2001; Zhang et al. 2006). The base of the models remained at a fixed elevation. The left, right, front and back boundaries were constrained to remain vertical. The top of each model was free to move in any direction (cf. Oliver et al. 2001; Sheldon et al. 2006). Thus the initial rectangular prism was deformed into a 
Fig. 4. Fault bend geometry with a cross-cutting fault (Model 18). See caption to Fig. 2 for definition of parameters.

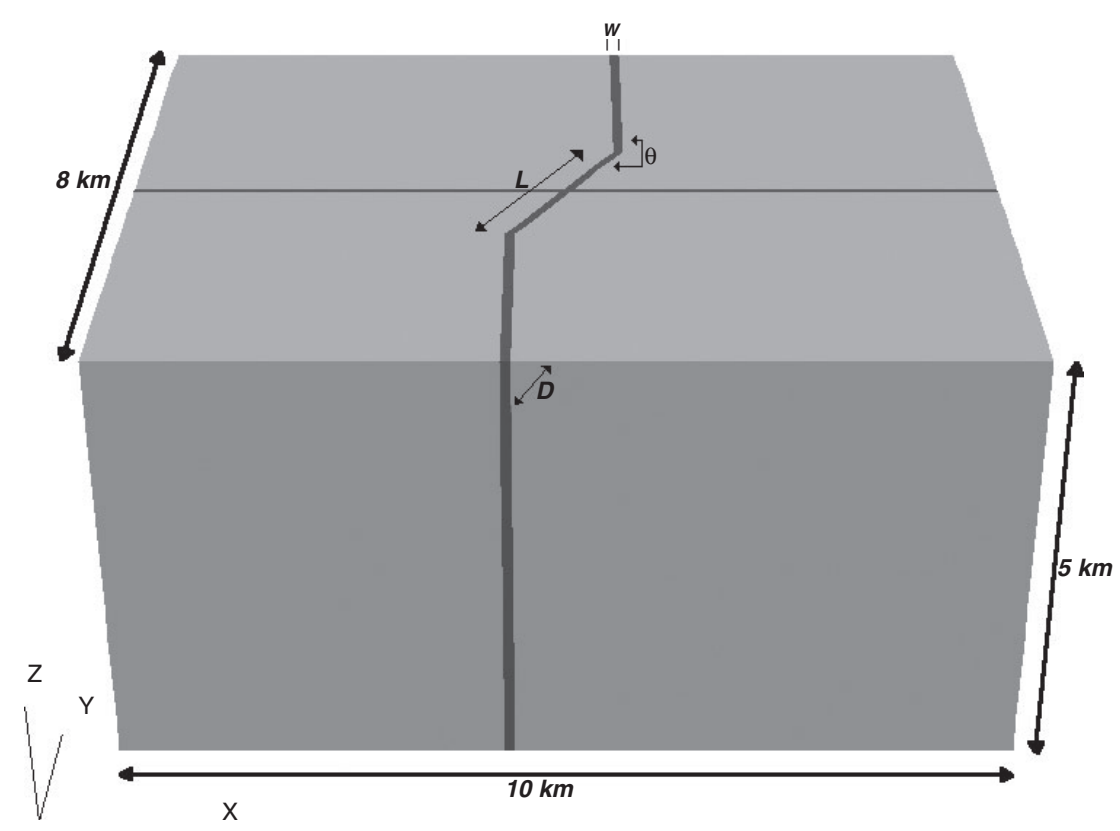

Table $2 \mathrm{FLAC}^{3 \mathrm{D}}$ defined material properties for the numerical models (cf. McLellan et al. 2004; Oliver et al. 2001).

\begin{tabular}{llllll}
\hline & ECV & MSG & Sybella & Urquhart & Fault \\
\hline Density $\left(\mathrm{kg} \mathrm{m}^{-3}\right)$ & 2700 & 2600 & 2650 & 2500 & 2700 \\
Bulk modulus $(\mathrm{Pa})$ & $2.7 \mathrm{e} 10$ & $4.0 \mathrm{e} 10$ & $4.95 \mathrm{e} 10$ & $2.8 \mathrm{e} 10$ & $2.7 \mathrm{e} 10$ \\
Shear modulus $(\mathrm{Pa})$ & $7.0 \mathrm{e} 9$ & $2.5 \mathrm{e} 10$ & $2.9 \mathrm{e} 10$ & $6.7 \mathrm{e} 9$ & $7.0 \mathrm{e} 9$ \\
Tensile strength $(\mathrm{Pa})$ & $1.0 \mathrm{e} 7$ & $3.5 \mathrm{e} 6$ & $4.0 \mathrm{e} 5$ & $1.2 \mathrm{e} 6$ & 0 \\
Cohesion $(\mathrm{Pa})$ & $2.0 \mathrm{e} 7$ & $7.0 \mathrm{e} 7$ & $4.0 \mathrm{e} 6$ & $3.0 \mathrm{e} 6$ & $2.0 \mathrm{e} 2$ \\
Dilation angle $(\mathrm{deg})$ & 3 & 3 & 3 & 3 & 4 \\
Friction angle $(\mathrm{deg})$ & 30 & 30 & 30 & 30 & 20 \\
Permeability $\left(\mathrm{m}^{2}\right)$ & $1 \mathrm{e}-18$ & $1 \mathrm{e}-19$ & $2 \mathrm{e}-19$ & $1 \mathrm{e}-19$ & $1 \mathrm{e}-16$ \\
Porosity $(\%)$ & 5 & 5 & 5 & 5 & 5 \\
\hline
\end{tabular}

ECV, Eastern Creek Volcanics (metabasalts); MSG, Myally Subgroup (quartzite); Sybella, Sybella Granite; Urquhart, Urquhart Shale.

parallelepiped with a rhombic base. The models were shortened $10 \%$ through the application of velocity boundary conditions with the shortening direction set at $112.5^{\circ}$ to be consistent with previous models of syn- $\mathrm{D}_{3}$ copper mineralization (McLellan 2006; McLellan \& Oliver 2007). This boundary condition resulted in dominantly sinistral strike-slip faulting such that the fault bend/jog was releasing with positive $\theta$ and restraining with negative $\theta$. Further models were run with contrasts in rock type and no faults, which allowed comparisons to be made with outputs from the different fault geometries. Models containing both contrasting rock types and faults were also tested.

Several outputs from the models were investigated, including pore pressure, mean stress, shear strain increment, volumetric strain and integrated fluid flux. However, this study focuses on absolute values and gradients in volumetric strain (dilation) and integrated fluid flux because of their critical importance in ore genesis.

\section{RESULTS}

The volumetric strain and integrated fluid flux were evaluated within the fault zone (from the maximum values and 99th percentile values, P99) and in areas proximal to the fault zone (from the 90th percentile values, P90). Detailed examination of several models implies that the 99th percentile value occurs only within the fault zone, and that at the 90th percentile, the values are proximal to, but outside the fault zone (with the exception of the models with a cross-cutting fault, in which case the P90 values also occur within the fault zone). These criteria were applied to examine the magnitude of dilation and fluid flow in and around the fault, and to determine how well the fault and/or surrounding host rock acted as fluid flow pathways or barriers.

\section{Effect of fault dip variation}

There is a variation in dilation of approximately two orders of magnitude for fault bend models, and one order of magnitude for fault jog models, between the maximum values seen in the $45^{\circ}$ dip fault models, and the maximum values seen in the remainder of the fault bend models with vertical dips (cf. Fig. 5A). Having a lower dip produces much less contrast in integrated fluid flux values (Fig. 5B). Fault bend models produce higher dilation and integrated fluid flux values than the 
(A)

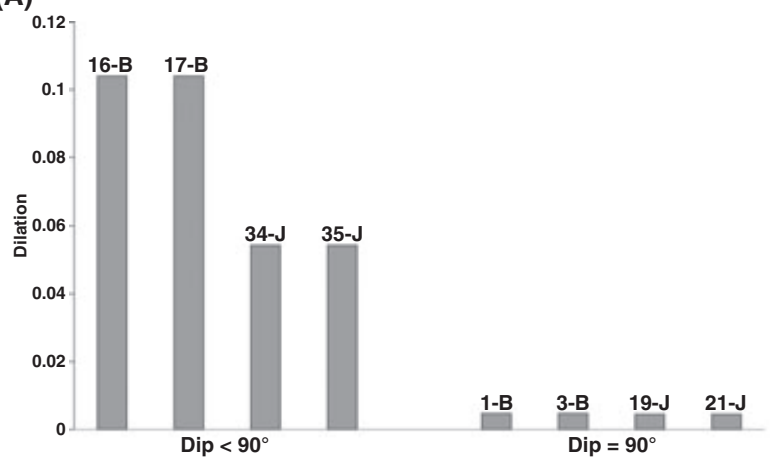

(C)

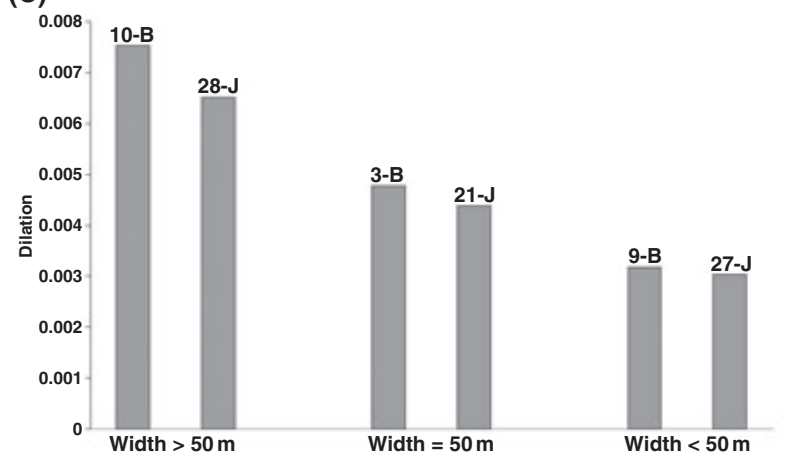

(E)

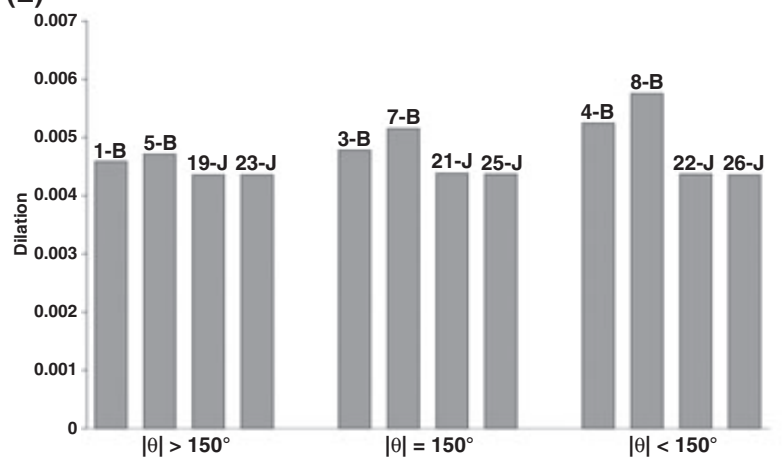

(G)

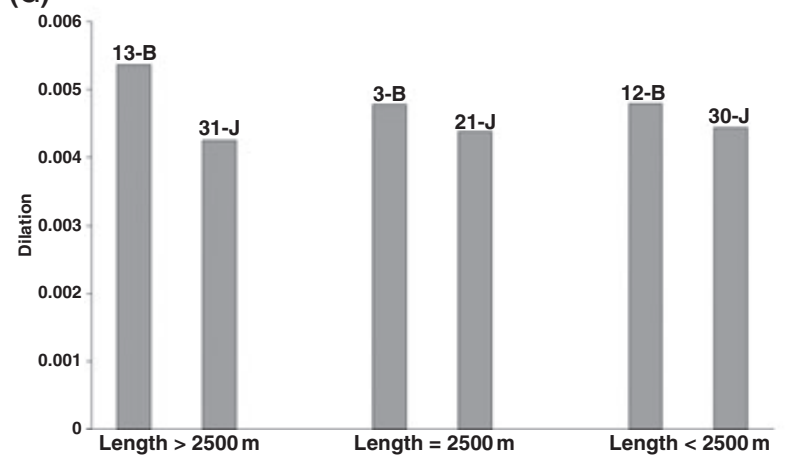

(B)

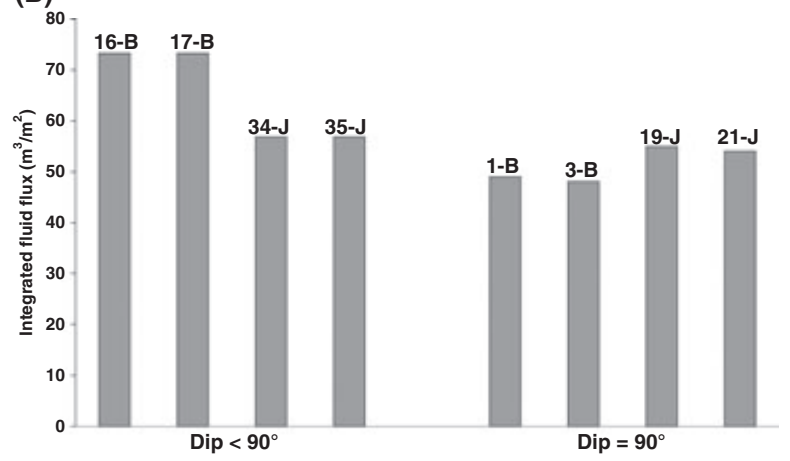

(D)

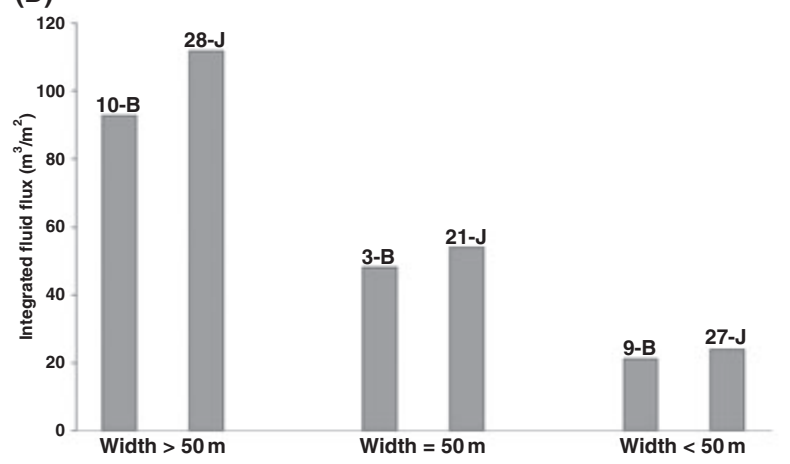

(F)

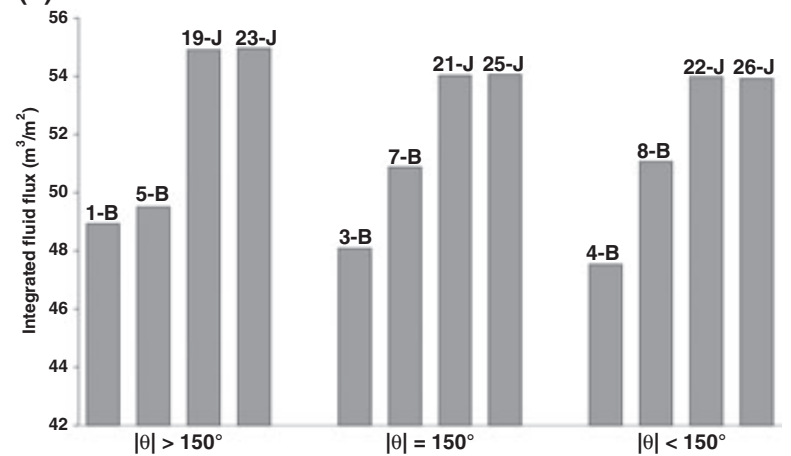

(H)

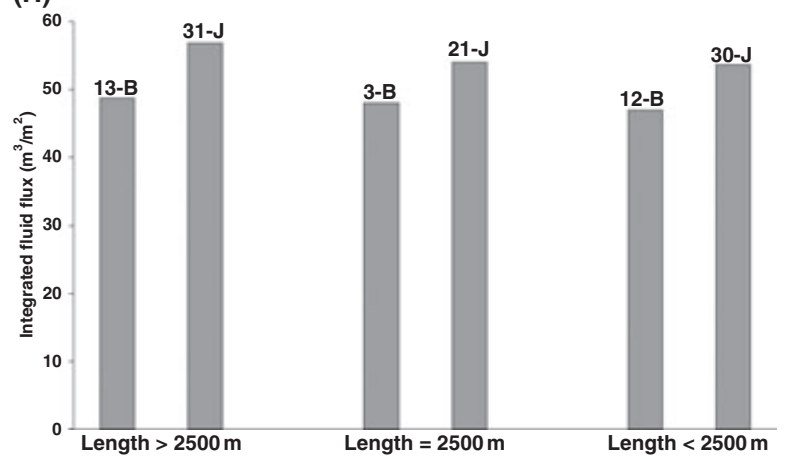

Fig. 5. Maximum dilation and integrated fluid flux values. Values for the continuous fault geometry variables from selected fault bend (b) and fault jog (j) models. Illustration of maximum (A) dilation for variation of fault dip, (B) integrated fluid flux for variation of fault dip, (C) dilation for variation of fault width, (D) integrated fluid flux for variation of fault width, (E) dilation for variation of bend/jog angle, (F) integrated fluid flux for variation of bend/jog angle, (G) dilation for variation of bend/jog length, and $(\mathrm{H})$ integrated fluid flux for variation of bend/jog length. 
(A)

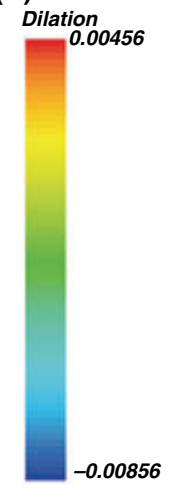

(B)

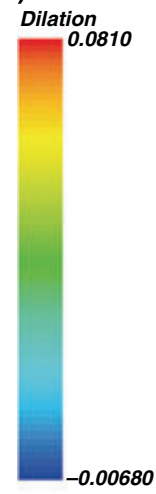

(C)

\section{Dilation}

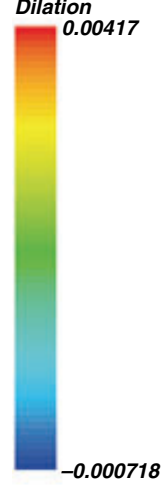

(D)

\section{Dilation}

Dilation 0.0445

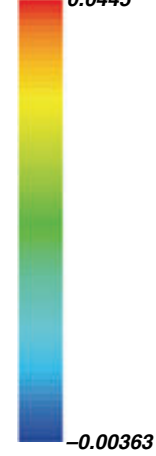

(E)

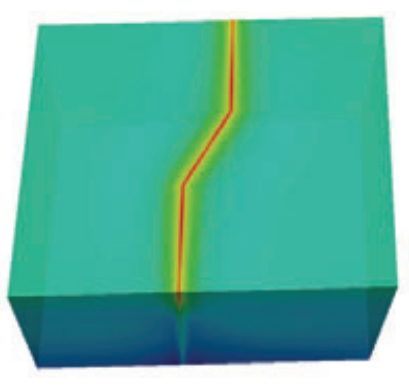

I.F.F. $\left(m^{3} m^{-2}\right)$

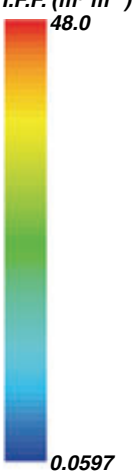

(F)

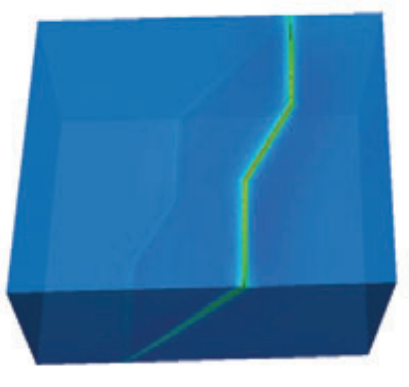

I.F.F. $\left(m^{3} m^{-2}\right)$

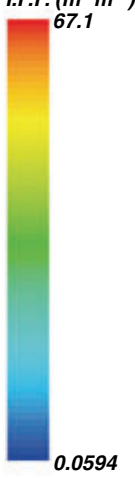

(G)

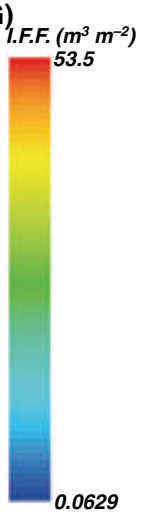

(H)

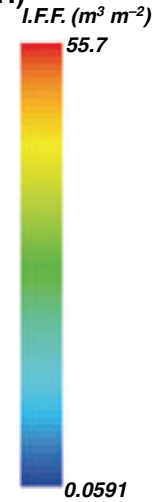

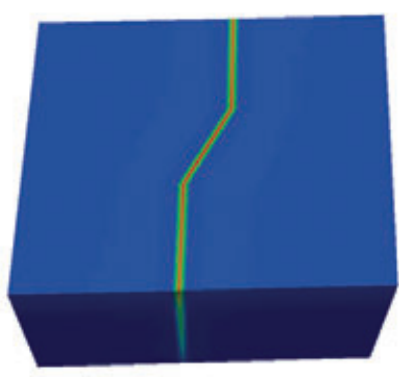
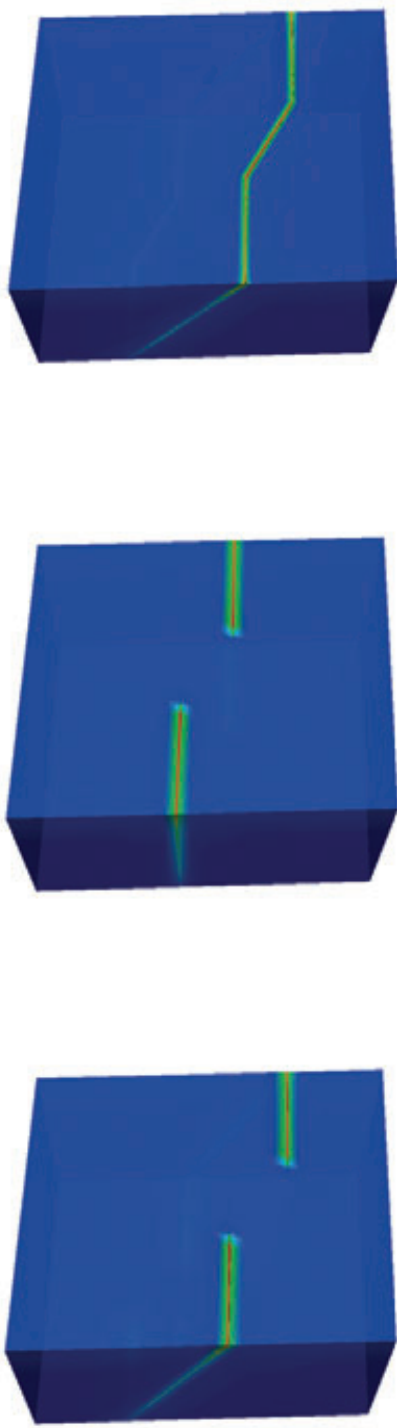

Fig. 6. Effect of varying fault dip. The effect of varying fault dip $D$ on dilation (left column, A-D) and integrated fluid flux (right column, E-H). Greater dilation and integrated fluid flux is demonstrated in models with a low fault dip. (A) Model 3 (B) Model 17 (C) Model 21 (D) Model 35 (E) Model 3 (F) Model 17 (G) Model $21(\mathrm{H})$ Model 35.

(c) 2008 The Authors

Journal compilation (C) 2008 Blackwell Publishing Ltd, Geofluids, 9, 2-23 
Table 3 Dilation and integrated fluid flux for each model (parameters defined in Table 1).

\begin{tabular}{|c|c|c|c|c|c|c|c|c|}
\hline \multirow[b]{2}{*}{ Model } & \multicolumn{4}{|l|}{ Dilation } & \multicolumn{4}{|c|}{ Integrated Fluid Flud $\left(\mathrm{m}^{3} / \mathrm{m}^{2}\right)$} \\
\hline & Min. & Max. & P99 & P90 & Min. & Max. & P99 & P90 \\
\hline 1 & -9.9957 & 0.0045916 & 0.003300 & 0.0011000 & 0.060835 & 48.938 & 31.94540 & 1.3807 \\
\hline \multicolumn{9}{|l|}{$2^{*}$} \\
\hline 3 & -9.9881 & 0.0047777 & 0.003320 & 0.0010510 & 0.0595210 & 48.075 & 31.03960 & 1.3665 \\
\hline 4 & -9.9986 & 0.0052442 & 0.003668 & 0.0010730 & 0.0598910 & 47.547 & 30.11160 & 1.3816 \\
\hline 5 & -9.9978 & 0.0047066 & 0.003420 & 0.0011250 & 0.0615960 & 49.494 & 32.22520 & 1.3994 \\
\hline 6 & -9.9474 & 0.0048596 & 0.003579 & 0.0011760 & 0.0625540 & 50.085 & 32.44010 & 1.4243 \\
\hline 7 & -9.9608 & 0.0051560 & 0.003865 & 0.0012650 & 0.0641120 & 50.884 & 32.57670 & 1.4703 \\
\hline 8 & -9.9742 & 0.0057495 & 0.004256 & 0.0013420 & 0.0652630 & 51.061 & 32.08060 & 1.5113 \\
\hline 9 & -9.945 & 0.0031817 & 0.001952 & 0.0008520 & 0.0211790 & 21.119 & 9.33520 & 0.4249 \\
\hline 10 & -9.9959 & 0.0075258 & 0.005963 & 0.0013269 & 0.1348600 & 92.824 & 73.87140 & 3.3814 \\
\hline 11 & -9.9991 & 0.0047835 & 0.003356 & 0.0010600 & 0.0533690 & 41.582 & 26.42750 & 1.2003 \\
\hline 12 & -9.9987 & 0.0047855 & 0.003383 & 0.0010490 & 0.0599990 & 46.995 & 30.94880 & 1.3680 \\
\hline 13 & -9.9919 & 0.0053665 & 0.003270 & 0.0010350 & 0.0593960 & 48.685 & 31.16200 & 1.3578 \\
\hline 14 & -9.9919 & 0.0051070 & 0.003523 & 0.0010590 & 0.0585990 & 48.274 & 30.95300 & 1.3683 \\
\hline 15 & -9.9994 & 0.0051111 & 0.003525 & 0.0010590 & 0.0586010 & 48.273 & 30.95280 & 1.3682 \\
\hline 16 & -9.9952 & 0.1040800 & 0.052024 & 0.0013960 & 0.0572730 & 73.238 & 32.05700 & 1.6376 \\
\hline 17 & -9.9965 & 0.1040900 & 0.052020 & 0.0013960 & 0.0572730 & 73.239 & 32.05700 & 1.6376 \\
\hline 18 & -9.9552 & 0.0061809 & 0.004122 & 0.0013400 & 0.0382670 & 31.323 & 30.30220 & 9.1121 \\
\hline 19 & -9.9906 & 0.0043538 & 0.002381 & 0.0011040 & 0.0628920 & 54.891 & 26.67700 & 1.4139 \\
\hline 20 & -9.9842 & 0.0043685 & 0.002101 & 0.0010960 & 0.0627060 & 54.290 & 26.53190 & 1.4148 \\
\hline 21 & -9.9345 & 0.0043768 & 0.002141 & 0.0010830 & 0.0627570 & 54.015 & 26.51690 & 1.4161 \\
\hline 22 & -9.9961 & 0.0043683 & 0.002075 & 0.0010760 & 0.0633790 & 53.966 & 26.54420 & 1.4169 \\
\hline 23 & -9.9896 & 0.0043569 & 0.002370 & 0.0011050 & 0.0635100 & 54.956 & 26.73180 & 1.4143 \\
\hline 24 & -9.9511 & 0.0043796 & 0.002105 & 0.0010960 & 0.0634110 & 54.377 & 26.63090 & 1.4159 \\
\hline 25 & -9.9603 & 0.0043755 & 0.002120 & 0.0010800 & 0.0631720 & 54.047 & 26.62090 & 1.4183 \\
\hline 26 & -9.9938 & 0.0043630 & 0.002052 & 0.0010800 & 0.0630190 & 53.929 & 26.64090 & 1.4199 \\
\hline 27 & -9.974 & 0.0030299 & 0.001630 & 0.0009010 & 0.0219310 & 23.976 & 7.67004 & 0.4387 \\
\hline 28 & -9.9972 & 0.0065196 & 0.003397 & 0.0013920 & 0.1513800 & 111.730 & 73.65290 & 3.6167 \\
\hline \multicolumn{9}{|l|}{$29^{*}$} \\
\hline 30 & -9.9765 & 0.0044328 & 0.002894 & 0.0010910 & 0.0622300 & 53.609 & 32.95950 & 1.4192 \\
\hline 31 & -9.9598 & 0.0042553 & 0.001892 & 0.0011030 & 0.0633640 & 56.888 & 26.14500 & 1.3999 \\
\hline 32 & -9.9795 & 0.0045570 & 0.002170 & 0.0010900 & 0.0621210 & 54.161 & 26.44690 & 1.4147 \\
\hline 33 & -9.9701 & 0.0045587 & 0.002173 & 0.0010940 & 0.0621120 & 54.162 & 26.44680 & 1.4147 \\
\hline 34 & -9.9995 & 0.0542770 & 0.023420 & 0.0011500 & 0.0567750 & 56.790 & 19.74770 & 1.4319 \\
\hline 35 & -9.9916 & 0.0542670 & 0.023770 & 0.0011530 & 0.0567600 & 56.795 & 19.74170 & 1.4320 \\
\hline 36 & -9.9948 & 0.0043140 & 0.003928 & 0.0013000 & 0.0388560 & 34.715 & 31.83790 & 7.6720 \\
\hline 37 & -9.9378 & 0.0084830 & 0.008175 & 0.0066540 & 1.5584000 & 83.833 & 72.42420 & 56.0800 \\
\hline 38 & -9.9745 & 0.0076240 & 0.006274 & 0.0038940 & 1.3938000 & 89.283 & 78.49820 & 61.9240 \\
\hline 39 & -9.9978 & 0.0056916 & 0.004554 & 0.0028537 & 0.0132980 & 46.605 & 28.24780 & 1.3790 \\
\hline 40 & -9.9858 & 0.0055398 & 0.003300 & 0.0016433 & 0.0043400 & 49.155 & 35.63460 & 1.4556 \\
\hline 41 & -9.9989 & 0.0194200 & 0.010607 & 0.0019331 & 0.0036670 & 34.138 & 30.50600 & 11.8495 \\
\hline 42 & -9.9953 & 0.0066363 & 0.004363 & 0.0018050 & 0.0044140 & 29.892 & 27.72020 & 8.1681 \\
\hline 43 & -9.9102 & 0.0063940 & 0.004180 & 0.0017000 & 0.0044240 & 34.591 & 28.17440 & 7.2935 \\
\hline 44 & -9.9822 & 0.0122850 & 0.005204 & 0.0015097 & 0.0042630 & 35.980 & 33.22880 & 8.8498 \\
\hline
\end{tabular}

Min. and Max. are the minimum and maximum values, P99 and P90 are the 99th and 90th percentiles, respectively, and results are for $10 \%$ deformation with azimuth $=112.5^{\circ}$.

*Note: Model 2 and Model 29 failed to run to $10 \%$ shortening.

corresponding fault jog models within the fault zone (Fig. 6).

While models with a lower dip fault may have the highest maximum dilation and relatively high integrated fluid flux values, these highest values are focused entirely along the fault zone (cf. Fig. 6). There is a considerable drop in values for the dilation and integrated fluid flux in areas proximal to the fault zone (Table 3 ).

\section{Effect of fault width variation}

Wide faults produce comparatively high dilation values within the fault zone when compared with changes in other fault geometry variables (Table 3 ), with little difference observed between the values for the fault bend and fault jog models (Figs 5C and 7). The integrated fluid flux was highest in both fault bend and jog models with wider 
(A)

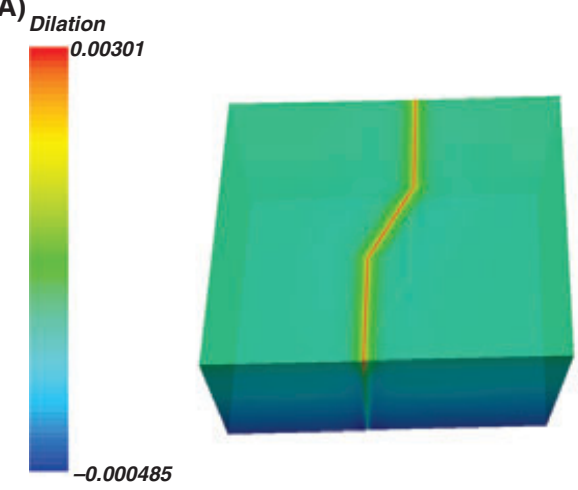

(B)

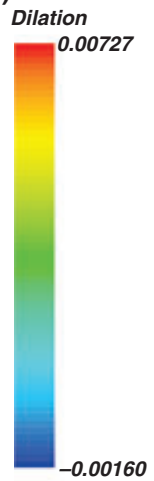

(C)

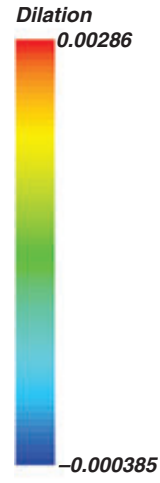

(D)

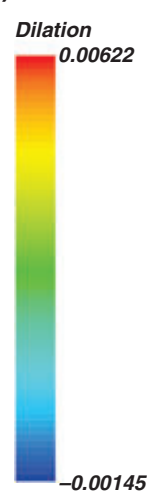

(E)

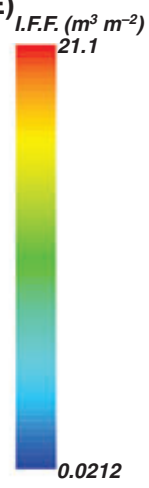

(F)

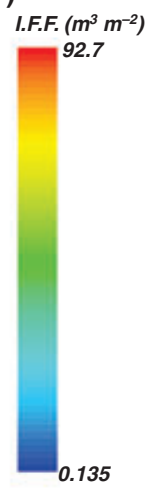

(G)

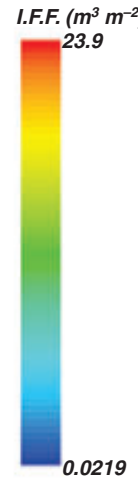

(H)

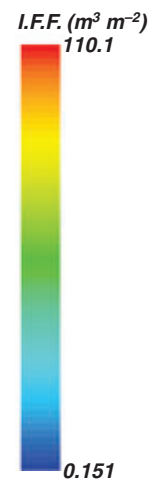

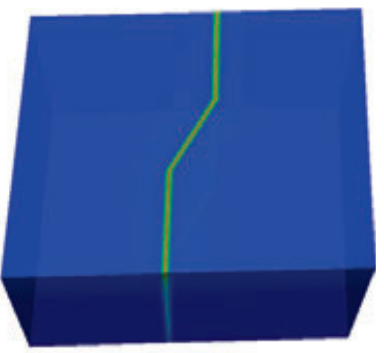
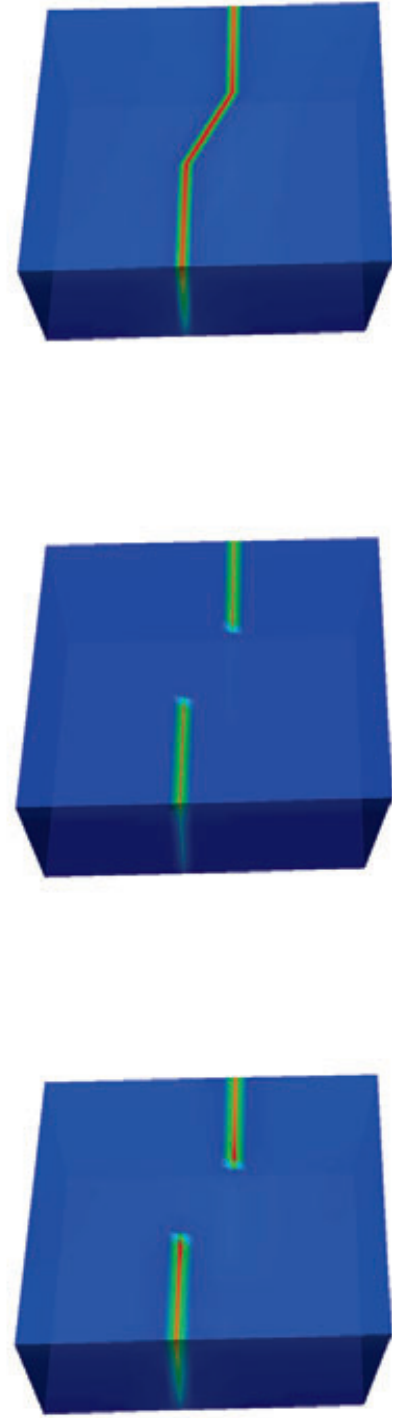

Fig. 7. Effect of varying fault width. The effect of varying fault width $w$ on dilation (left column, A-D) and integrated fluid flux (right column, E-H). Greater dilation and integrated fluid flux is demonstrated in models with a wider fault. (A) Model 9 (B) Model 10 (C) Model 27 (D) Model 28 (E) Model 9 (F) Model $10(\mathrm{G})$ Model $27(\mathrm{H})$ Model 28.

(c) 2008 The Authors

Journal compilation (c) 2008 Blackwell Publishing Ltd, Geofluids, 9, 2-23 
faults, with the fault jog models producing slightly higher values than fault bend models (Figs 5D and 7).

Dilation for fault bend models in areas proximal to the fault zone was found to drop considerably (Table 3), and these bend models with wide faults also produced less change in dilation when compared with changes in other fault geometry variables. For fault jog models, the greatest change in dilation was seen in the wide fault models when compared with changes in other fault geometry variables for areas proximal to the fault. A wide fault produces higher values of integrated fluid flux proximal to the fault zone than a narrow fault (Fig. 7), though the magnitude drops considerably with distance from the fault.

\section{Effect of bend/jog angle variation}

Fault bends produced higher dilation values within the fault zone as the absolute value of the angle $(\theta)$ of the bend decreased, but the fault jogs showed higher dilation as the absolute value of $\theta$ increased (see Table 3; Fig. 5E). The difference in dilation values within the fault zone as $\theta$ is varied is much greater for the fault bends than the fault jogs, with the maximum values for the fault jogs displaying very minor changes with $\theta$. Similar results were obtained for the integrated fluid flux values (Figs $5 \mathrm{~F}$ and 8 ). It is interesting to note that the models with a restraining bend or jog geometry displayed similar results to the releasing fault geometries (Table 3; Fig. 5E,F). In comparison with other geometry variables, having a favorable fault bend or fault jog angle did not produce particularly high dilation or integrated fluid flux values within the fault zone.

In areas proximal to the fault zone, decreased absolute values of $\theta$ produced higher dilation and integrated fluid flux values for fault bend models (Table 3; Fig. 8). However, fault jog models produce higher dilation values proximal to the fault for larger absolute jog angles, and higher integrated fluid flux for smaller absolute jog angles in areas proximal to the fault zone (Fig. 8). As with values within the fault zone, the variation of $\theta$ generates a greater difference in values in areas proximal to the fault zone for the fault bend models than the corresponding fault jog models. The change in integrated fluid flux was not particularly high outside the fault zone in comparison with the changes due to variation of other fault geometry parameters. However, the change in dilation for fault bend models outside the fault zone was high in comparison with changes due to variation of other parameters.

\section{Effect of bend/jog length variation}

Varying the length of the fault bends showed that models with longer bends had higher dilation within the fault zone (see Table 3; Figs 5G and 9). However, the fault jog models were found to have higher values of dilation for shorter fault jog lengths (Figs 5G and 9). The integrated fluid flux values in the fault bend models also displayed higher values within the fault zone for longer fault bend lengths (Fig. 5H; Table 3). Changes in fault bend length had less effect on integrated fluid flux values than other fault geometry variables. Conversely, changing fault jog length produced large increases in integrated fluid flux values in comparison with changes in other fault geometry variables, and produced higher increases than corresponding fault bend models (Table 3 ). In the areas proximal to the fault zone, the length of the fault bend or fault jog produced the lowest effect on dilation and integrated fluid flux values when compared with varying other fault geometry variables (Table 3 ). The integrated fluid flux in the area surrounding the fault zone was higher in fault bend models with a longer bend, and in fault jog models with a shorter jog, but the dilation was higher in models with a shorter bend length and in models with a longer jog length (Fig. 9), though these values were all very similar.

\section{Effect of a cross-cutting fault}

The inclusion of a cross-cutting fault on the fault bend models produced higher dilation within the fault zone than a similar model without the cross-cutting fault (Table 3; Fig. 10). However, an additional fault did not produce as much extra dilation as decreasing the dip of the fault and widening the fault. Within the fault zone, models with a cross-cutting fault generated lower dilation values than other models (Table 3; Fig. 10). The integrated fluid flux within the fault zone was found to be the lowest with the inclusion of a cross-cutting fault compared with the other models for both fault bend and fault jog cases.

The presence of a cross-cutting fault produced considerably higher integrated fluid flux values compared with changes in other fault geometries in areas proximal to the fault zone for both the fault bend and fault jog models (Table 3). However, the dilation values in this area did not vary much compared with values from the other models.

\section{Effect of rock-type variation}

Little difference is seen in the dilation values when the fault is replaced by a contrast in rock type. However, an increase is seen in the integrated fluid flux at the lithological boundary (Table 3; Fig. 11A,B,E,F). In areas proximal to the lithological boundaries, the presence of more rock types produces lower dilation than in models with fewer rock types. In contrast, the integrated fluid flux is higher in models with more rock types. In comparison to the variation of the fault geometry parameters, a contrast in rock types generates relatively large changes in dilation and integrated fluid flux. Integrated fluid flux increases proximal to the lithological boundaries are at least an order of 
(A)

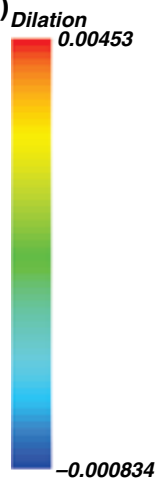

(B)

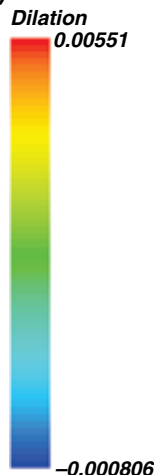

(C)

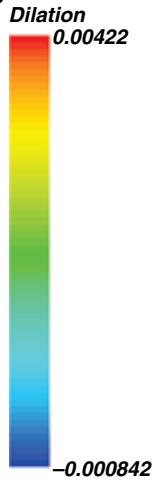

(D)

Dilation

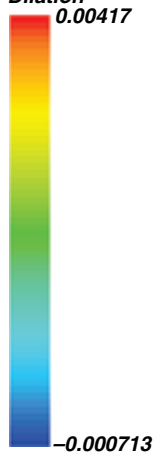

(E)
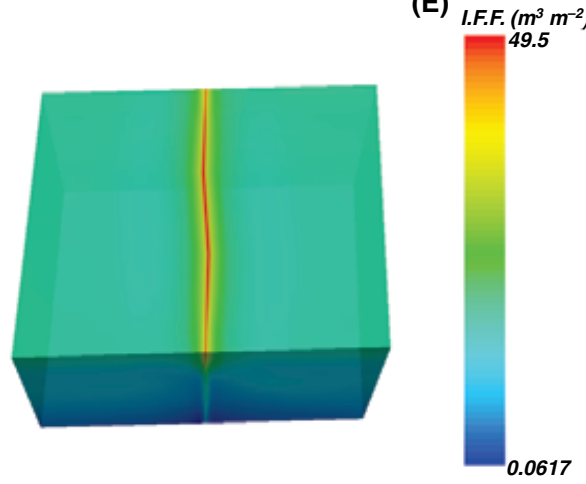

(F)

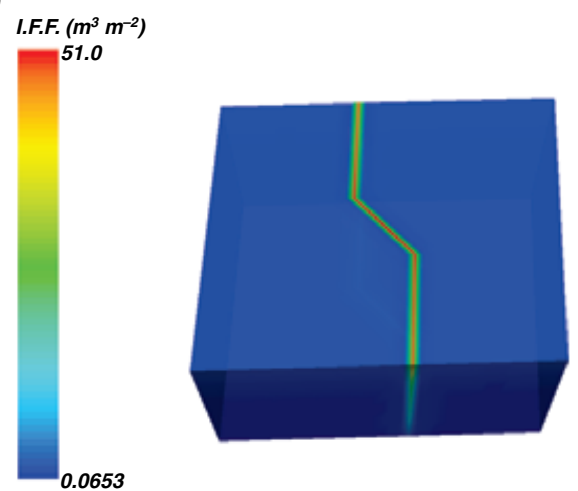

(G)

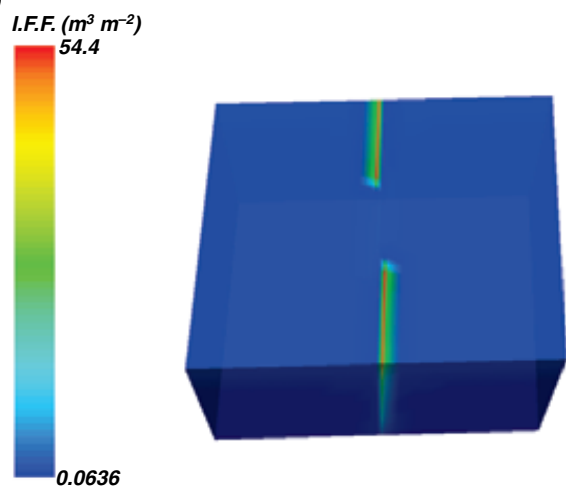

(H)

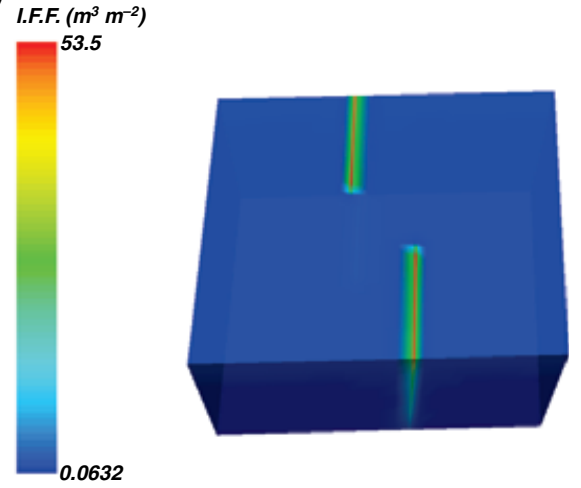

Fig. 8. Effect of varying fault bend/jog angle. The effect of varying fault bend/jog angle $\theta$ on dilation (left column, A-D) and integrated fluid flux (right column, E-H). Greater dilation and integrated fluid flux is demonstrated in fault bend models with a large absolute bend angle and in fault jog models with a small absolute jog angle. (A) Model 5 (B) Model 8 (C) Model 23 (D) Model 26 (E) Model 5 (F) Model 8 (G) Model 23 (H) Model 26.

(c) 2008 The Authors

Journal compilation (c) 2008 Blackwell Publishing Ltd, Geofluids, 9, 2-23 
(A)

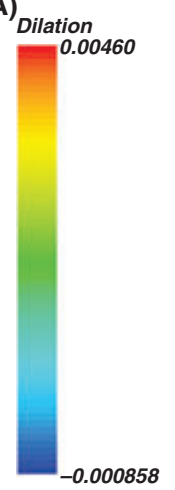

(B)

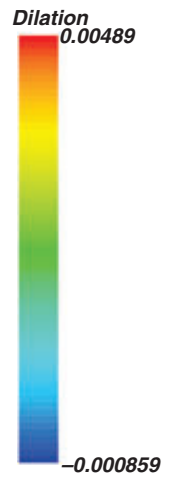

(C)

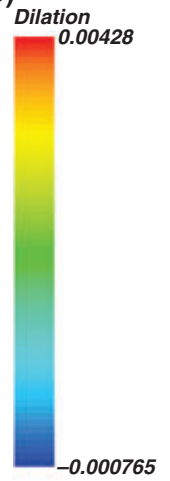

(D)

\section{Dilation} 0.00409

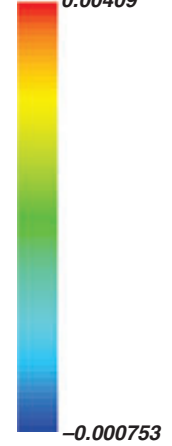

(E)
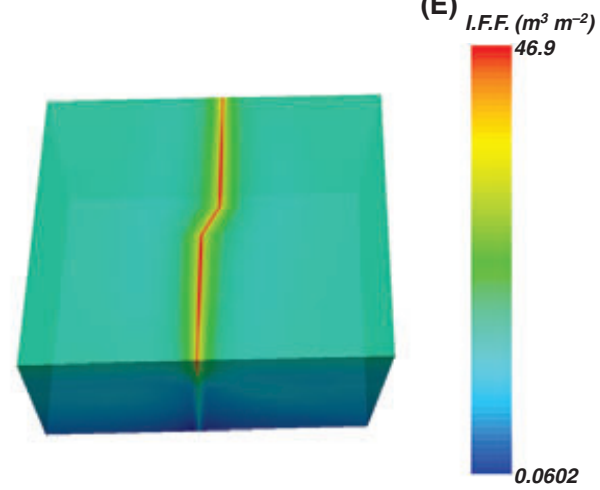

(F)

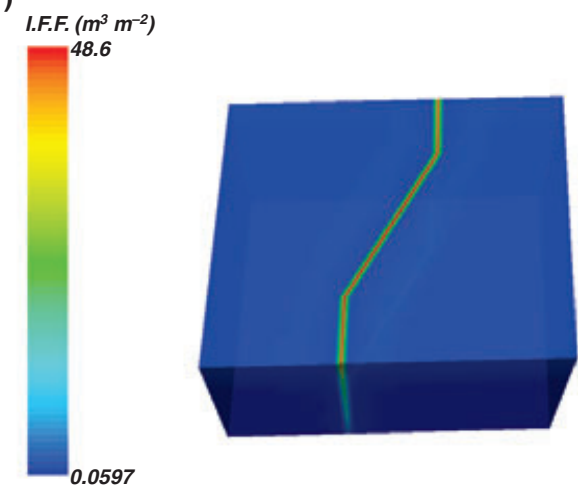

(G)

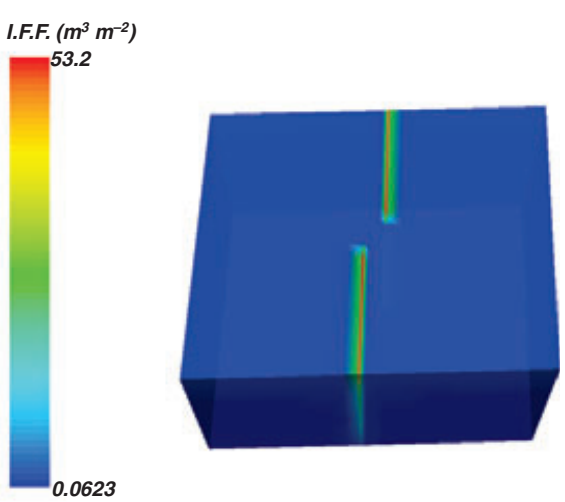

(H)
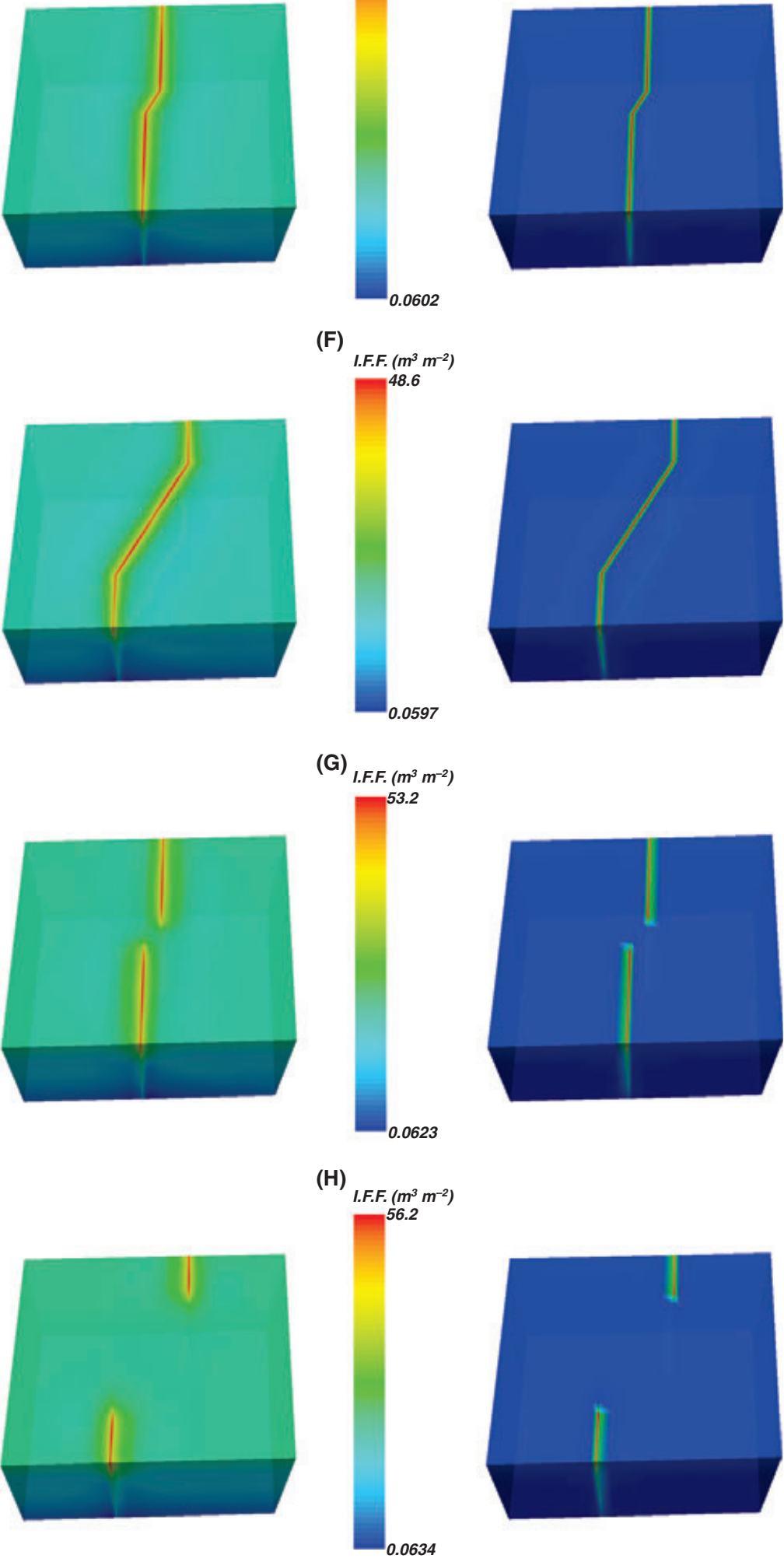

Fig. 9. Effect of varying fault bend/jog length. The effect of varying fault bend/jog length $L$ on dilation (left column, A-D) and integrated fluid flux (right column, E-H). Greater dilation and integrated fluid flux is demonstrated in fault bend models with a large bend length and in fault jog models with a small jog length. (A) Model 12 (B) Model 13 (C) Model 30 (D) Model 31 (E) Model 12 (F) Model 13 (G) Model 30 (H) Model 31. 
(A) Dilation

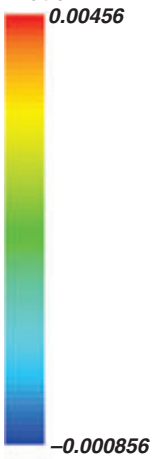

(B)

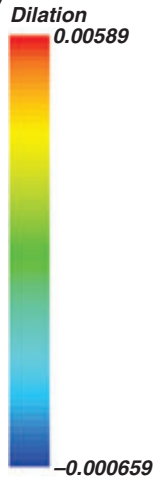

(C)

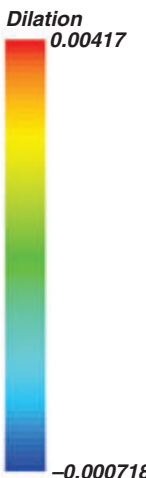

(D)

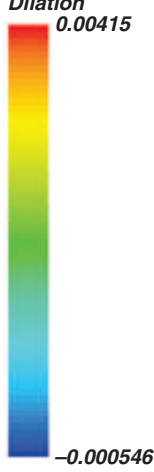

(E)
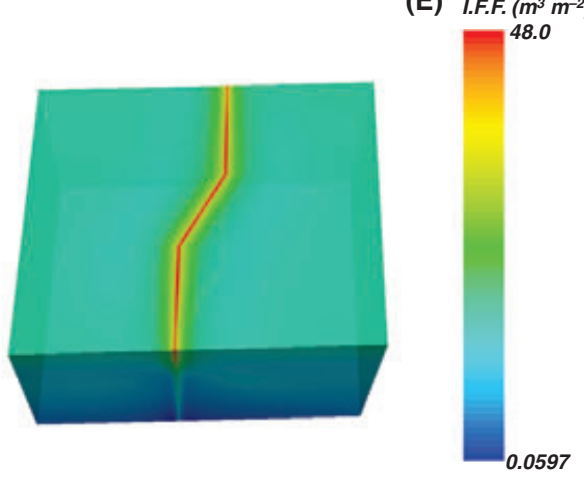

(F)

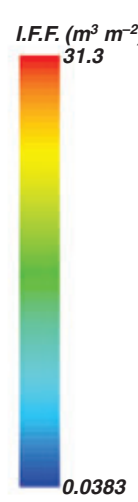

(G)
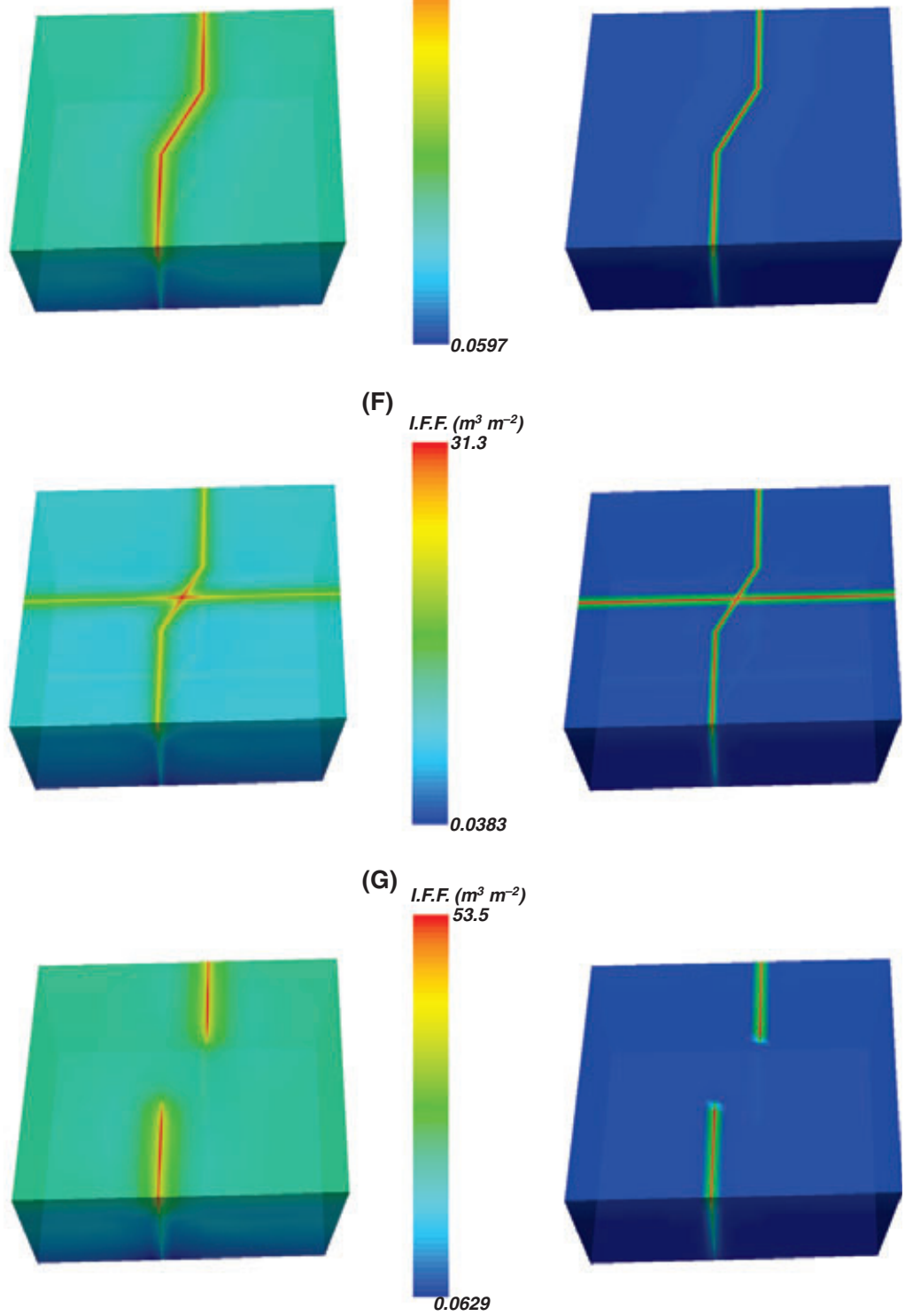

(H)
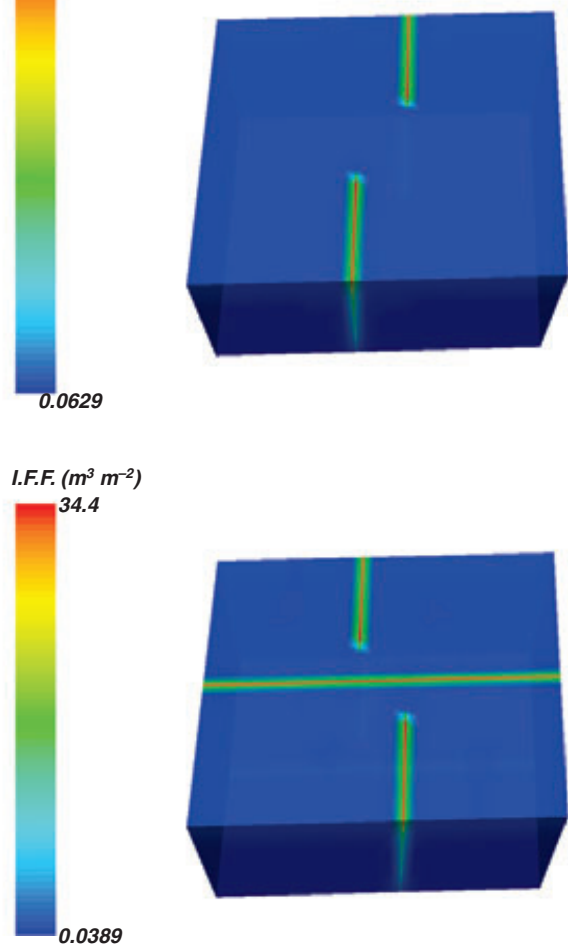

Fig. 10. Effect of adding a cross-cutting fault. The effect of inclusion of an EW cross-cutting fault on dilation (left column, A-D) and integrated fluid flux (right column, E-H). Greater dilation and integrated fluid flux is demonstrated in models containing a cross-cutting fault. (A) Model 3 (B) Model 18 (C) Model 21 (D) Model 36 (E) Model 3 (F) Model 18 (G) Model 21 (H) Model 36.

\section{(c) 2008 The Authors}

Journal compilation (c) 2008 Blackwell Publishing Ltd, Geofluids, 9, 2-23 
(A)

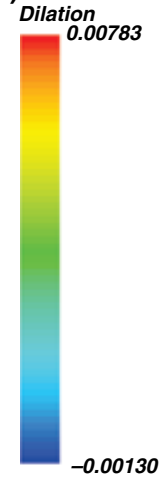

(B)

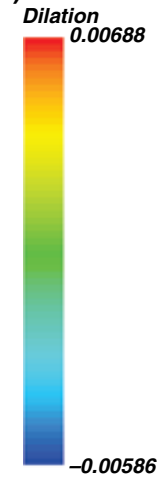

(C)

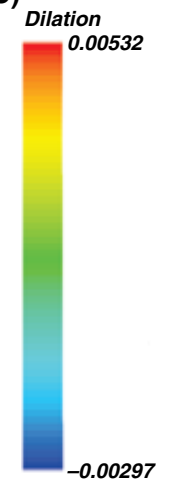

(D)

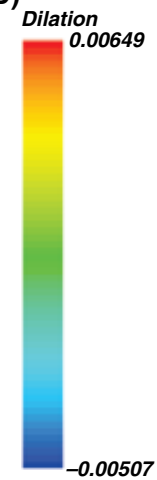

(E)

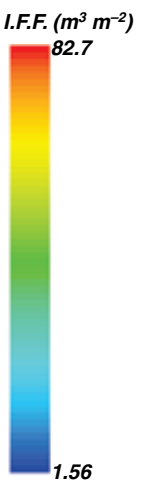

(F)

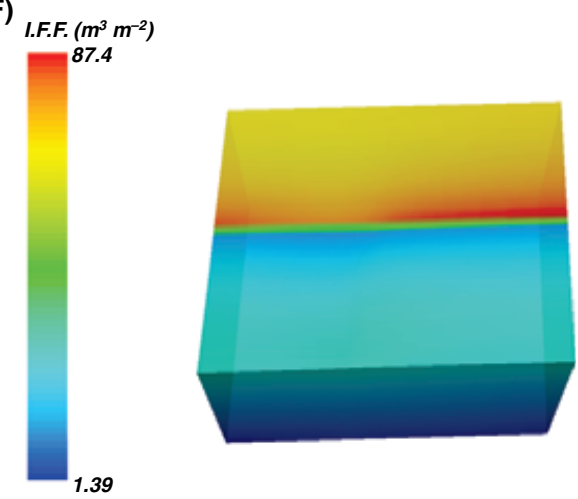

(G)

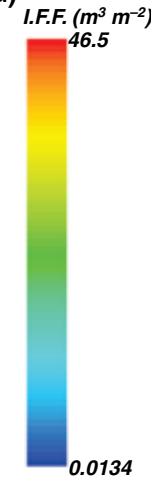

(H)

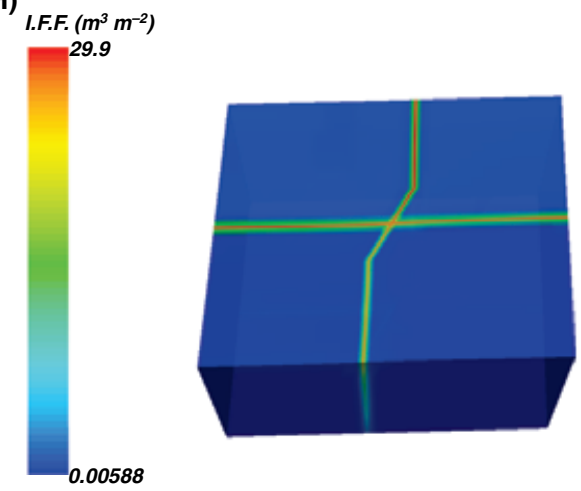

Fig. 11. Effect of adding contrast in rock types. The effect of varying rock types on dilation (left column, A-D) and integrated fluid flux (right column, E-H). $(A),(B),(E)$ and $(F)$ illustrate the dilation and integrated fluid flux in models with the fault removed and replaced by a contrast in rock type. (C), (D), (G) and (H) illustrate the dilation and integrated fluid flux in models containing a fault and a contrast in rock type. (A) Model 37 (B) Model 38 (C) Model 40 (D) Model 42 (E) Model 37 (F) Model 38 (G) Model 40 (H) Model 42. 
magnitude higher than the increases seen in the same area due to varying the fault geometry parameters.

Reintroducing the fault to the models with a contrast in rock types indicates that it is not simply the presence of a greater number of rock types which produces the highest dilation and integrated fluid flux values, but that the different material properties (such as the shear strength) assigned to the rocks have a large effect (Fig. 11C,D,G,H). Larger amounts of dilation (by an order of magnitude) were observed in the models with rock types seen in the Gunpowder region (Eastern Creek Volcanics and Myally Quartzite) compared with those models with the rock types seen in the Mount Isa region (Eastern Creek Volcanics, Urquhart Shale, and Sybella Granite). Although the integrated fluid flux values varied much less, slightly higher values were still generated in the Gunpowder rock-type models than the Mount Isa rock-type models.

\section{Dilation and integrated fluid flux ratios}

The model results were evaluated by the ratios between the highest and lowest values of dilation and integrated fluid flux, respectively (referred to as 'dilation ratio' and 'integrated fluid flux ratio'), which illustrate the extent to which these parameters are focused within the models. All dilation ratios are negative because they contrast a positive maximum value (expansion) with a negative minimum value (contraction). Some general patterns can be observed for the ratios for variation of a particular parameter (Fig. 12). Table 1 shows that the dilation ratio in each model is on the order of -0.0005 for the majority of models. Greater differences between the minimum and maximum dilation values (lower dilation ratios) are seen for models with a lower dip (Models 16, 17, 34, and 35), as well as some of the models with a contrast in rock types that represent the Gunpowder region (Models 41 and 44). Figure 12 illustrates that wider faults, smaller absolute bend angles, larger absolute jog angles, longer bend lengths and shorter jog lengths show greater differences between the minimum and maximum dilation values. For the majority of models, the integrated fluid flux ratio is on the order of 850 (Table 1). Higher integrated fluid flux ratios are seen in models with a lower dip, and a narrower fault jog. A larger absolute jog angle generates a higher integrated fluid flux ratio (Fig. 12); however, the variation of the ratio for the fault bend angle does not show a readily definable pattern. Both fault bend and fault jog geometries show a larger integrated fluid flux ratio for a longer bend or jog. Considerably higher ratios are seen in models containing a fault and contrast in rock types, in one case by two orders of magnitude (Model 40). However, in the models containing a contrast in rock types with no fault, the integrated fluid flux ratio is an order of magnitude lower than in the majority of the models.

\section{Fluid flow vectors}

Figure 13 shows the fluid flow vectors from the perspective of the front boundary for a selection of models. The top of the models demonstrates downward fluid flow, with greater flow occurring within the fault/shear zone. This locally downward flow at the top of the models reflects a greater degree of dilation around the embedded fault zone, thus drawing fluid towards the fault or shear zone from the free top boundary, as observed in other studies (e.g. Ord \& Oliver 1997). Such draw-down is particularly prominent in numerical models where the top model surface is equated with the Earth's surface (e.g. Oliver et al. 2006). Fluid flow below the top of the model is in an upward direction, again with the greatest flow occurring within the fault zone. In the model with contrasting rock types, downward fluid flow is observed for the top half of the model rather than just at the top boundary.

\section{DISCUSSION}

The models within this study have explored the effect of varying the geometry on strike-slip deformation and coupled fluid flow. The prospectivity of a variety of geological settings has been evaluated in previous numerical modelling studies through examining variation in permeability (Ord \& Oliver 1997), and stress orientation and magnitude (Rawling et al. 2006; Robinson et al. 2006; Schaubs et al. 2006; McLellan \& Oliver 2007). While it is critical to recognize how variation of these model parameters affects modelling results in order to understand the model implications for the genesis of ore deposits, it is also critical to understand how small changes in the input geometry can affect results (e.g. Schaubs et al. 2006).

Evaluation of the fault geometries by quantifying the dilation and integrated fluid flux both within the fault zone and in areas proximal to the fault zone provides an indication of what type of features are important for increasing the potential for mineralization of simple fault bend and jog geometries. Figure 5 illustrates the variation in maximum dilation and integrated fluid flux from selected models for the continuous parameters investigated in this study (fault dip, fault width, bend/jog angle and bend/jog length). The results suggest that maximum values of dilation and integrated fluid flux for fault geometries with $\mathrm{N}-\mathrm{S}$ striking faults containing a fault bend or jog are dominated by lower fault dips, contrasts in rock types, and wide faults. The maximum integrated fluid flux within fault bend models was dominated by wide faults, followed by a contrast in rock types, and a lower fault dip, whereas fault jog models were dominated by wide faults, a cross-cutting fault, and a contrast in rock types. 

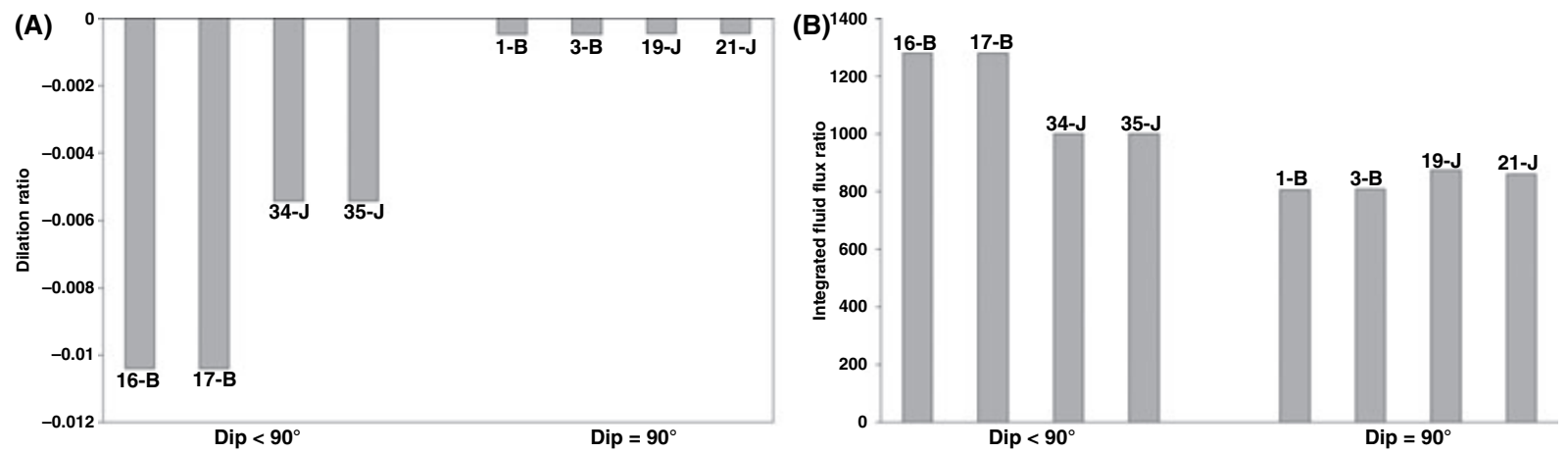

(C)

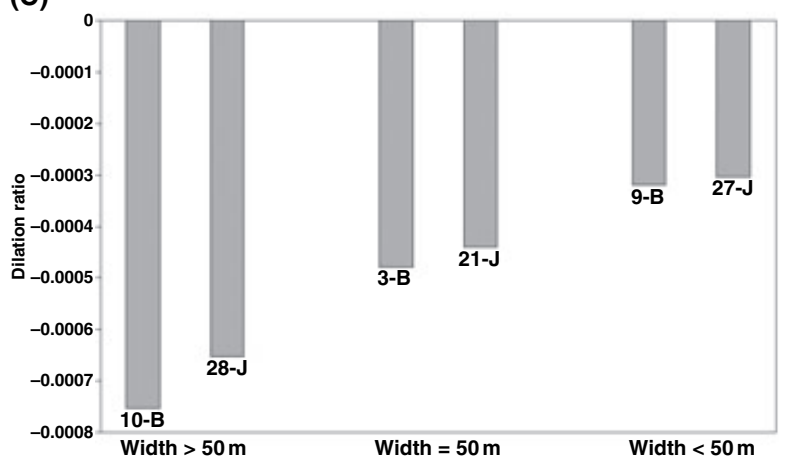

(E)

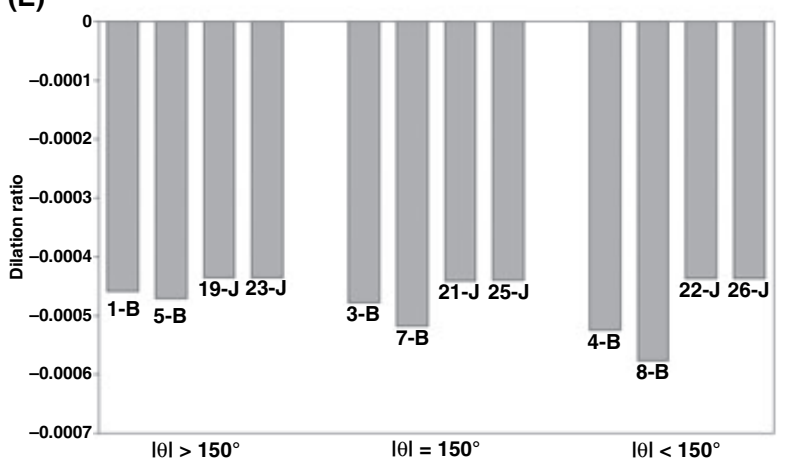

(G)

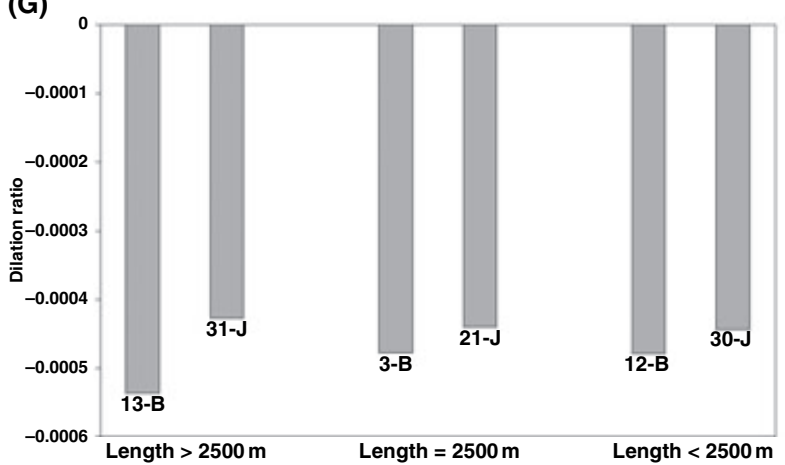

(D)

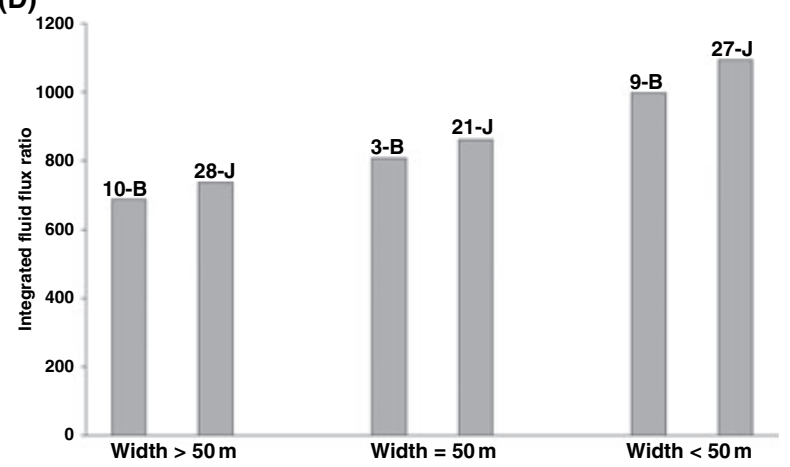

(F)

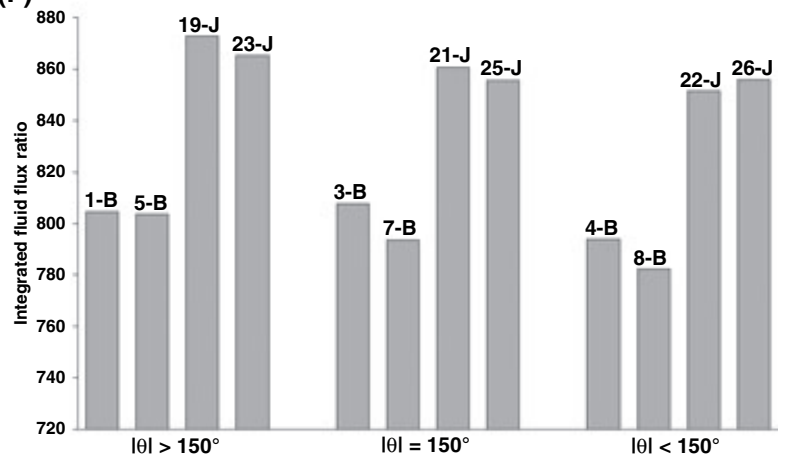

(H)

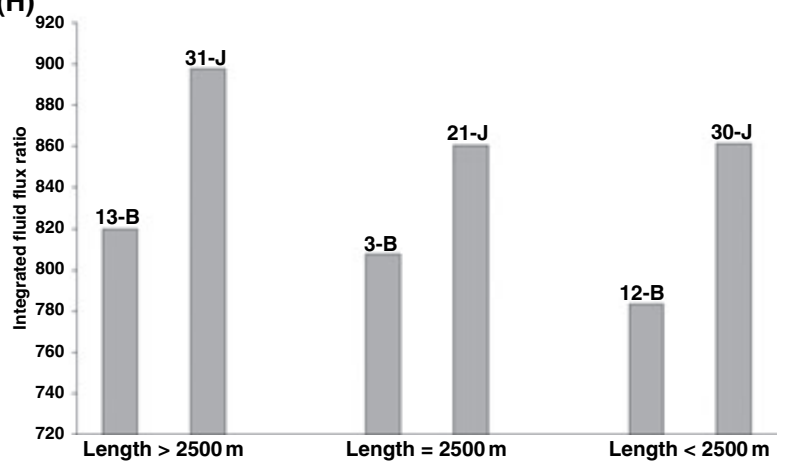

Fig. 12. Dilation and integrated fluid flux ratios. Ratios for the continuous fault geometry variables from selected fault bend (b) and fault jog (j) models. Illustration of (A) dilation ratio for variation of fault dip, (B) integrated fluid flux ratio for variation of fault dip, (C) dilation ratio for variation of fault width, (D) integrated fluid flux ratio for variation of fault width, (E) dilation ratio for variation of bend/jog angle, (F) integrated fluid flux ratio for variation of bend/jog angle, $(G)$ dilation ratio for variation of bend/jog length, and $(H)$ integrated fluid flux ratio for variation of bend/jog length.

Lower dips have a dominant effect on the outputs, with steep faults penetrating to the same depth as the low-dip faults resulting in less dilation and integrated fluid flux.
This could be due to two possible effects: the increased down-dip extent of a lower angle fault, or the lower-dip faults having less normal stress. 

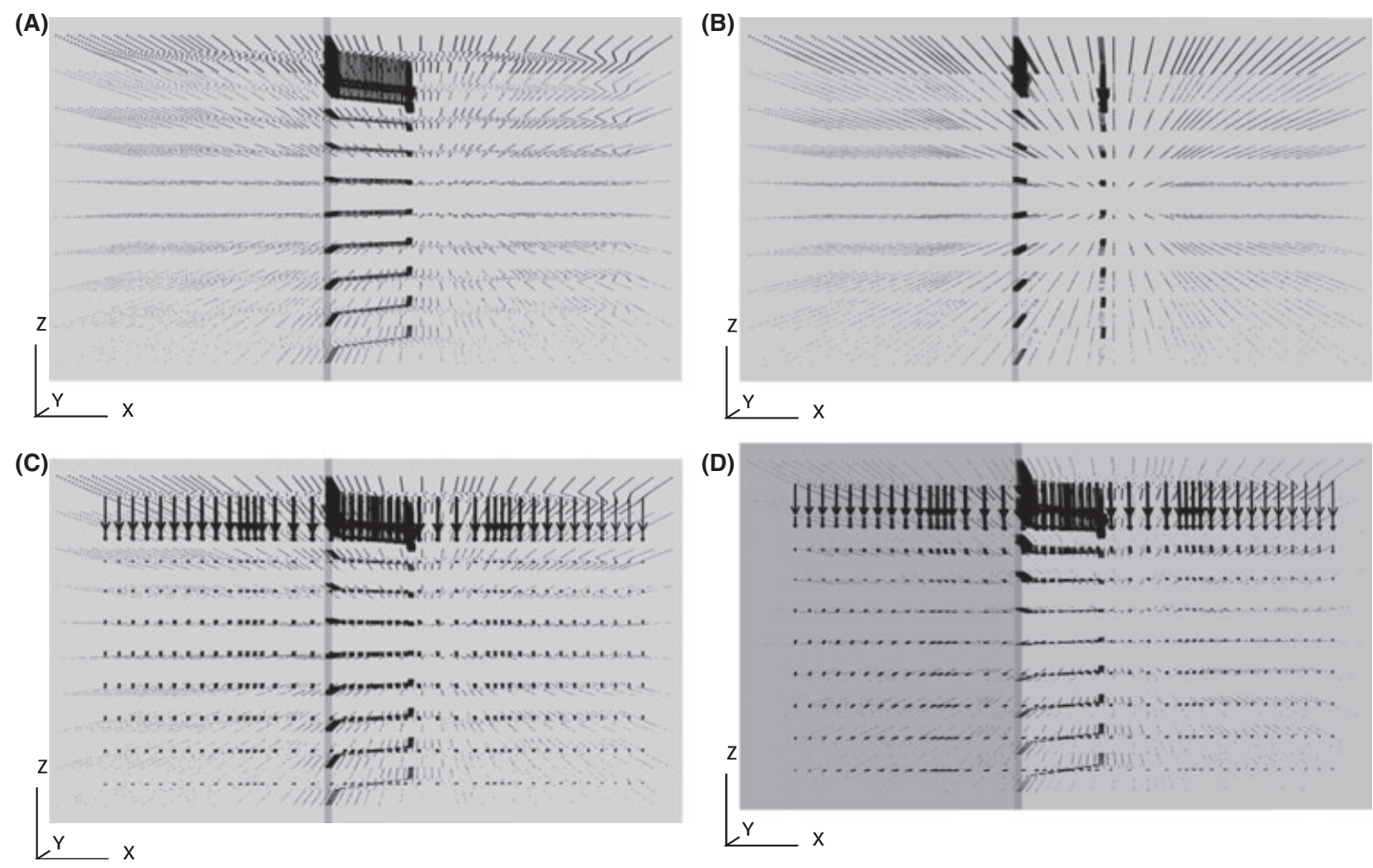

Fig. 13. Fluid flow vectors. (A) fault bend model (Model 3), (B) fault jog model (Model 21), (C) fault intersection model (Model 18), and (D) model with contrast in rock types (Model 42).

Wider faults can allow transfer of larger volumes of fluid than narrower faults, as demonstrated by the larger integrated fluid flux values seen in the models with wider faults. It is suggested that this is due to a greater volume of material with higher permeability within the fault zone in which the fluid can be focused.

An important result of the modelling is that dilation and integrated fluid flux values are similar in restraining and releasing fault bends and jogs (cf. Micklethwaite \& Cox 2004). Dilation can occur in restraining geometries in the model because of Mohr-Coulomb plasticity (or any other non-associated rheology) in which shear induces dilatancy (Vermeer \& de Borst 1984; Ord \& Oliver 1997). To the extent that the Mohr-Coulomb rheology is realistic (e.g. Oliver et al. 2001), this result challenges some approaches to prospectivity that focus on releasing geometries, and also helps to explain the location of ore bodies in both releasing and restraining bends/jogs (Allibone et al. 2002b).

The models suggest that similar changes to fault bend and jog geometries have opposite effects on the outputs. Dilation and integrated fluid flux are increased by fault bends that are longer and have smaller absolute bend angles, but by fault jogs that are shorter and have larger absolute jog angles. This interesting result can be explained by the effect of the higher fault permeabilities in the mod- els: the faults are two to three orders of magnitude more permeable than the adjacent rocks. A decrease in absolute fault jog angle or jog length results in higher dilation and integrated fluid flux because of more continuity along the en echelon fault segments, resulting in less interruption to fluid flow. However, an increase in absolute fault bend angle or an increase in the bend length results in greater dilation and integrated fluid flux within the fault. The highest dilation values occur in the bend for the largest absolute bend angles. In the models with a bend angle of $\pm 135^{\circ}$, the highest dilation values occur at the tips of the $\mathrm{N}-\mathrm{S}$ trending part of the fault directly proximal to the bend. It is possible that higher shear strains on the longer fault bends, or the larger absolute bend angles, lead to more dilation. Further modelling work is required to verify the reasons for fault bend length and angle producing such results.

The presence of the intersecting fault in both the bend and jog models changed the dilation and integrated fluid flux compared with models without the intersecting fault. However, changes in other fault geometry variables, particularly having favorable fault dips and widths, produced even greater changes.

In the models containing a contrast in rock type across the fault (Fig. 11C,D,G,H), the faults can act as juxtaposition seals (Knipe 1992, 1993) rather than conduits for 
fluid flow, because they juxtapose lower permeability rocks contrasted against higher permeability rocks. Figure 13D shows that the deformation has started to create a fold at the top of the model. As this feature is only observed in the models with a contrast in rock type (Fig. 13A,B,C), the juxtaposition of the lower and higher permeability rocks may be a critical factor in the generation of this type of structure. It is also possible that this fold is partly responsible for the increased downward fluid flow seen in Fig. 13D.

It is interesting to note that the integrated fluid flux ratios are broadly consistent with the permeability contrast between the fault and the host rocks, so that the variability in this ratio can be attributed to geometric factors. The ratios suggest that models with a low fault dip and those with a contrast in lithology across a fault have the greatest capacity for focusing both dilation and integrated fluid flux (Fig. 12). The concentration of dilation and fluid flux in small areas is critical in models for describing the formation of hydrothermal ore deposits (de Wijs 1951; Turcotte 1989).

Potential limitations of the numerical modelling performed in this study include the fixed and higher permeabilities used for the fault, and the boundary conditions applied. A fixed permeability for the fault and rock types through the model run was used so that the effect of fault geometries could be isolated, rather than adding variable permeability due to deformation, which would require a more complex analysis. Faults can be transiently permeable during rupture. The models accommodate this effect by assigning a higher permeability to the faults, effectively integrating the increased permeability over time.

As a result of computational limitations, the models were not run over a sufficient real-time equivalent to produce high enough integrated fluid flux values to form an ore deposit. However, it is the underlying deformation processes, strain partitioning and fluid flow regime which are important factors in this study. Although the strain rate after $10 \%$ shortening is faster than most natural strain rates, the comparisons between models with different geometries are unlikely to be affected significantly (cf. Oliver et al. 2006).

Although the shortening direction of $112.5^{\circ}$ is considered to be representative at the time of copper mineralization in the Western Succession of the Mount Isa Inlier (McLellan 2006), this study did not test other shortening directions which may potentially have produced greater dilation and integrated fluid flux values for the fault geometries under investigation. The boundary conditions imposed on each of the models were set to focus on strike-slip deformation (appropriate to the strike-slip kinematics of many major faults in the Western Succession), so that, for example, the effect of pure transpression was not examined. Furthermore, the results presented were analyzed only after a shortening of $10 \%$. Preliminary inspection of the models results at lower values suggests that the same patterns reported here are consistent through the deformation history. Although the geometries and modelling parameters examined in this study were chosen for their applicability to the western Mount Isa Inlier, the results could be adapted to other regions with similar fault geometries, provided that Mohr-Coulomb plasticity is appropriate. Different fault geometries, boundary conditions, mechanical behaviours, and material properties could be assigned, as appropriate for other study areas. These limitations open up many possibilities for future studies.

Table 4 summarizes the fault geometry variables which could be used as ingredients for prospectivity analysis. These combinations of fault system variables should therefore produce the most favorable conditions for hydrothermal mineralization which can be applied to copper mineralization in the Western Succession of the Mount Isa Inlier and could feasibly be incorporated into an exploration targeting program.

Both absolute values and gradients (ratios) have been suggested as important factors for mineralization (Phillips 1972; Oliver \& Bons 2001). Absolute values may be more appropriate when considering ore deposition dominated by infill in fault chambers, whereas the ratios may be more appropriate when ore genesis requires wall rock reactions to contribute chemically. As both the absolute values and ratios for dilation and integrated fluid flux are examined in this study, either set of results could be used for targeting, depending on the ore genesis model being examined.

The majority of the effects seen in the models are consistent with the dominant influence of strain-induced dilation on fluid flow, combined with the higher permeabilities ascribed to the faults. These two factors can explain the effects of fault dip, width, and bend and jog length and angle. Some of the results may be challenging to conventional ideas of prospectivity: e.g. restraining and releasing bends are equally favorable, and changes in length or angle have opposite effects in bends compared with jogs.

Table 4 Ranking of ingredients for prospectivity analysis in strike slip fault systems in decreasing order of sensitivity.

\begin{tabular}{ll}
\hline Fault bends & Fault jogs \\
\hline Low fault dip & Low fault dip \\
Contrast in rock types & Contrast in rock types \\
Wide fault & Wide fault \\
Cross-cutting fault & Cross-cutting fault \\
Large absolute bend angle & Small absolute jog angle \\
Long bend & Short jog \\
\hline
\end{tabular}




\section{CONCLUSIONS}

Dilation and integrated fluid flux are critical factors in the genesis of ore deposits. This study shows how numerical modelling of three-dimensional strike-slip coupled deformation and fluid-flow models can be used to rank fault geometry variables that are important for generating higher dilation and integrated fluid flux values or gradients through quantitative analysis of the model outputs.

Analysis of fault system variables indicates which values for these variables produce higher dilation and integrated fluid flux values or ratios. In order of priority, dilation is maximized by: a low fault dip, a contrast in rock types, a wide fault, a cross-cutting fault and for fault bends, a small bend angle and long bend, and for fault jogs, a large jog angle and a short jog. Integrated fluid flux is maximized by a wide fault, a contrast in rock types, and a low fault dip; and for fault bends, a small bend angle and long bend, and for fault jogs, a large jog angle and a short jog length, and a cross-cutting fault. Increasing the length or angle of fault bends has opposite effects to those observed for fault jogs. Restraining and releasing fault bend and jog geometries show similar results, indicating the dominant effect of strain-induced dilatancy in these models. These conclusions can be directly extrapolated into the field so that exploration can focus on areas with most favorable fault system parameters, provided that the Mohr-Coulomb plasticity used in the models is appropriate.

\section{ACKNOWLEDGEMENTS}

This paper is published with the permission of the Chief Executive Officer, predictive mineral discovery Cooperative Research Centre $\left(p m d^{\star} \mathrm{CRC}\right)$. This study is part of the $\mathrm{PhD}$ research by the senior author at James Cook University which is supported by a $p m d^{\star} \mathrm{CRC}$ scholarship. The authors would like to acknowledge the support of the Computational Geoscience group at CSIRO in Perth, particularly Heather Sheldon, for assistance with the numerical modelling. Nick Oliver is thanked for providing constructive comments on the manuscript.

\section{REFERENCES}

Allibone AH, McCuaig TC, Harris D, Etheridge M, Munroe S, Byrne D, Amanor J, Gyapong W (2002a) Structural controls on gold mineralization at the Ashanti Deposit, Obuasi, Ghana. In: Integrated Methods for Discovery: Global Exploration in the Twenty-First Century (eds Goldfarb RJ, Nielsen RL), Society of Economic Geologists, Special Publication. 9, 65-93.

Allibone AH, Teasdale J, Cameron G, Etheridge M, Uttley P, Soboh A, Appiah-Kubi J, Adanu A, Arthur R, Mamphey J, Odoom B, Zuta J, Tsikata A, Pataye F, Famiyeh S, Lamb E (2002b) Timing and structural controls on gold mineralization at the Bosogo Gold Mine, Ghana, West Africa. Economic Geology, 97, 949-69.

Bell TH, Perkins WG, Swager CP (1988) Structural controls on development and localization of syntectonic copper mineralization at Mount Isa, Queensland. Economic Geology, 83, 6985.

Blake DH, Stewart AJ (1992) Stratigraphic and tectonic framework, Mount Isa Inlier. In: AGSO Bulletin 243: Detailed Studies of the Mount Isa Inlier (eds Stewart AJ, Blake DH), pp. 1-11. Australian Geological Survey Organisation, Canberra.

Blake DH, Etheridge MA, Page RW, Stewart AJ, Williams PR, Wyborn LAI (1990) Mount Isa Inlier - regional geology and mineralization. In: Geology of the Mineral Deposits of Australia and Papua New Guinea (ed. Hughes FE), pp. 915-25. Australian Institute of Mining and Metallurgy, Melbourne.

Bonson CG, Childs C, Walsh JJ, Schöpfer MPJ, Carboni V (2007) Geometric and kinematic controls on the internal structure of a large normal fault in massive limestones: The Maghlaq Fault, Malta. Journal of Structural Geology, 29, 336-54.

Brankman CM, Aydin A (2004) Uplift and contractional deformation along a segmented strike-slip fault system: the Gargano Promontory, southern Italy. Journal of Structural Geology, 26, 807-24.

Chester FM, Chester JS (2000) Stress and deformation along wavy frictional faults. Journal of Geophysical Research, 105, 2342130.

Chester JS, Fletcher RC (1997) Stress distribution and failure in anisotropic rock near a bend on a weak fault. Journal of Geophysical Research, 102, 693-708.

Cox SF (1999) Deformational controls on the dynamics of fluid flow in mesothermal gold systems. In: Fractures, Fluid Flow and Mineralization (eds Lonergan L, Wilkinson JJ, McCaffrey KJW), The Geological Society, Special Publication, 155, 12340.

Cox SF (2005) Coupling between deformation, fluid pressures, and fluid flow in ore-producing hydrothermal systems at depth in the crust. In: Economic Geology One Hundredth Anniversary Volume (eds Hedenquist JW, Thompson JFH, Goldfarb RJ, Richards JP), pp. 39-75. Society of Economic Geologists, Littleton.

Craw D (2000) Fluid flow at fault intersections in an active oblique collision zone, southern Alps, New Zealand. Journal of Geochemical Exploration, 69, 70, 523-6.

Drummond BJ, Goleby BR, Goncharov AG, Wyborn LAI, Collins CDN, MacCready T (1998) Crustal-scale structures in the Proterozoic Mount Isa Inlier of north Australia: their seismic response and influence on mineralisation. Tectonophysics, 288, 43-56.

Egan SS, Kane S, Buddin TS, Williams GD, Hodgetts D (1999) Computer modelling and visualisation of the structural deformation caused by movement along geological faults. Computers o Geosciences, 25, 283-97.

Feltrin L, Oliver NHS, Kelso IJ, King S (2003) Basement metal scavenging during basin evolution: Cambrian and Proterozoic interaction at the Century $\mathrm{Zn}-\mathrm{Pb}-\mathrm{Ag}$ Deposit, Northern Australia. Journal of Geochemical Exploration, 78/79, 159-62.

Ford A, Blenkinsop TG (2007) Combining fractal analysis of mineral deposit clustering with weights of evidence to evaluate patterns of mineralization: application to copper deposits of the Mount Isa Inlier. Ore Geology Reviews, 33, 435-50.

Ford A, Blenkinsop TG (2008) Evaluating geological complexity and complexity gradients as controls on copper mineralisation, Mt Isa Inlier. Australian Journal of Earth Sciences, 55, 13 23. 
Garven G, Bull SW, Large RR (2001) Hydrothermal fluid flow models of stratiform ore genesis in the McArthur Basin, Northern Territory, Australia. Geofluids, 1, 289-311.

Gessner K, Jones PA, Wilde AR, Kühn M (2006) Significance of strain localization and fracturing in relation to hydrothermal mineralization at Mount Isa, Australia. Journal of Geochemical Exploration, 89, 129-32.

Gibson GM, Hitchman AP (2005) Il Final Report: 3D Basin Architecture and Mineral Systems in the Mt Isa Western Succession $p m d^{*} C R C$ [Unpublished report], p. 268.

Gow PA, Upton P, Zhao C, Hill KC (2002) Copper-gold mineralisation in New Guinea: numerical modelling of collision, fluid flow and intrusion-related hydrothermal systems. Australian Journal of Earth Sciences, 49, 753-71.

Heinrich CA, Bain JHC, Mernagh TP, Wyborn LAI, Andrew AS, Waring CL (1995) Fluid and mass transfer during metabasalt alteration and copper mineralization at Mount Isa, Australia. Economic Geology, 90, 705-30.

Hodkiewicz PF, Weinberg RF, Gardoll SJ, Groves DI (2005) Complexity gradients in the Yilgarn Craton: fundamental controls on crustal scale fluid-flow and the formation of world-class orogenic-gold deposits. Australian Journal of Earth Sciences, $\mathbf{5 2}, 831-41$.

Itasca Consulting Group (2002) FLAC3D: Fast Lagrangian Analysis of Continua in 3 Dimensions. Itasca, Minneapolis, MN.

Knipe RJ (1992) Faulting processes and fault seal. Norwegian Petroleum Society (NPF), Special Publication 1, 325-42.

Knipe RJ (1993) The influence of fault zone processes and diagenesis on fluid flow. American Association of Petroleum Geologists Studies in Geology, 36, 135-54.

Laing WP (1998) Structural-metasomatic environment of the East Mt Isa Block base-metal-gold province. Australian Journal of Earth Sciences, 45, 413-28.

MacCready T, Goleby BR, Goncharov A, Drummond BJ, Lister GS (2006) Shifts in the locus of crustal thickening during Mesoproterozoic orogenesis in the Mt Isa Terrane. Australian Journal of Earth Sciences, 53, 41-53.

Mark G, Williams PJ, Boyce AJ (2004) Low-latitude meteoric fluid flow along the Cloncurry Fault, Cloncurry District, NW Queensland, Australia: geodynamic and metallogenic implications. Chemical Geology, 207, 117-32.

Matthäi SK, Heinrich CA, Driesner T (2004) Is the Mount Isa copper deposit the product of forced brine convection in the footwall of a major reverse fault? Geology, 32, 357-60.

McDonald GD, Collerson KD, Kinny PD (1997) Late Archean and Early Proterozoic crustal evolution of the Mount Isa block, northwest Queensland, Australia. Geology, 25, 1095-8.

McLellan JG (2006) Discrete Element Modelling of the Isa Inlier Predictive Mineral Discover: Science at the Sharp End. Predictive Mineral Discovery CRC, University of Western Australia, Perth, pp. 25.

McLellan JG, Oliver NHS (2007) Discrete element modelling applied to copper prospectivity in the eastern Mount Isa Inlier. Precambrian Research, 163, 174-88.

McLellan JG, Oliver NHS, Schaubs PM (2004) Fluid flow in extensional environments; numerical modelling with an application to Hamersley iron ores. Journal of Structural Geology, 26, 1157-71.

Micklethwaite S, Cox SF (2004) Fault-segment rupture, aftershock-zone fluid flow, and mineralization. Geology, 32, 813-6.

Nijman W, Mijnlieff HF, Schalkwijk G (1992) The Hero Fan delta (Lower Mount Isa Group) and its structural control: deformation in the Hero/Western Fault Zone and Paroo Range compared, Proterozoic, Mount Isa Inlier, Queensland, Australia. In:
AGSO Bulletin 243: Detailed Studies of the Mount Isa Inlier (eds Stewart AJ, Blake DH), pp. 75-111. Australian Geological Survey Organisation, Canberra.

Oliver NHS, Bons PD (2001) Mechanisms of fluid flow and fluidrock interaction in fossil metamorphic hydrothermal systems inferred from vein-wallrock patterns, geometry and microstructure. Geofluids, 1, 137-62.

Oliver NHS, Ord A, Valenta RK, Upton P (2001) Deformation, fluid flow, and ore genesis in heterogeneous rocks, with examples and numerical models from the Mount Isa District, Australia. Society of Economic Geologists Reviews, 14, $51-74$.

Oliver NHS, McLellan JG, Hobbs BE, Cleverley JS, Ord A, Feltrin L (2006) 100th Anniversary special paper: Numerical models of extensional deformation, heat transfer, and fluid flow across basement-cover interfaces during basin-related mineralization. Economic Geology, 101, 1-31.

Ord A (1990) Mechanical controls on dilatant shear zones. In: Deformation Mechanisms, Rheology and Tectonics (eds Knipe RJ, Rutter EH), Geological Society, London, Special Publication, 54, $183-92$.

Ord A, Oliver NHS (1997) Mechanical controls on fluid flow during regional metamorphism: some numerical models. Journal of Metamorphic Geology, 15, 345-59.

Phillips WJ (1972) Hydraulic fracturing and mineralization. Journal of the Geological Society of London, 128, 337-59.

Queensland Department of Mines and Energy, Taylor Wall and Associates, SRK Pty Ltd and ESRI Australia (2000) North-West Queensland Mineral Province Report (NQMPR). Department of Mines and Energy, Brisbane.

Queensland Department of Natural Resources and Mines (2005) Mineral Occurrence and Geological Sites. Queensland Department of Natural Resources and Mines, Brisbane.

Rawling TJ, Schaubs PM, Dugdale LJ, Wilson CJL, Murphy FC (2006) Application of 3D models and numerical simulations as a predictive exploration tool in western Victoria. Australian Journal of Earth Sciences, 53, 825-39.

Robinson JA, Wilson CJL, Rawling TJ (2006) Numerical modelling of an evolving gold-lode system: structural and lithological controls on ore-shoot formation in the Magdala goldmine, western Victoria. Australian Journal of Earth Sciences, 53, 799823.

Sanderson DJ, Zhang X (1999) Critical stress localization of flow associated with deformation of well-fractured rock masses, with implications for mineral deposits. In: Fractures, Fluid Flow and Mineralization (eds McCaffrey KJW, Lonergan L, Wilkinson JJ), Geological Society, London, Special Publication $155,69-81$.

Schaubs PM, Rawling TJ, Dugdale LJ, Wilson CJL (2006) Factors controlling the location of gold mineralisation around basalt domes in the stawell corridor: insights from coupled 3D deformation-fluid-flow numerical models. Australian Journal of Earth Sciences, 53, 841-62.

Scott KM, Taylor GF (1982) Eastern Creek Volcanics as the source of copper at the Mammoth mine, Northwest Queensland. BMR Journal of Australian Geology \& Geophysics, 7, 93-8.

Sheldon HA, Barnicoat AC, Ord A (2006) Numerical modelling of faulting and fluid flow in porous rocks: an approach based on critical state soil mechanics. Journal of Structural Geology, 28, 1468-82.

Sorjonen-Ward P, Zhang Y, Zhao C (2002) Numerical modelling of orogenic processes and gold mineralisation in the southeastern part of the Yilgarn Craton, Western Australia. Australian Journal of Earth Sciences, 49, 935-64. 
Strayer LM, Hudleston PJ, Lonig LJ (2001) A numerical model of deformation and fluid-flow in an evolving thrust wedge. Tectonophysics, 335, 121-45.

Tripp GI, Vearncombe JR (2004) Fault/fracture density and mineralization: a contouring method for targeting in gold exploration. Journal of Structural Geology, 26, 1087-108.

Turcotte DL (1989) Fractals in geology and geophysics. In: Fractals in Geophysics (eds Scholz CH, Mandelbrot BB), pp. 171-96. Basel, Birkhauser.

Van Dijk PM (1991) Regional syndeformational copper mineralization in the western Mount Isa Block, Australia. Economic Geology, 86, 278-301.

Vermeer PA, de Borst R (1984) Non-associated plasticity for soils, concrete and rock. Heron, 29, 1-62.

Wang HF (2000) Theory of Poroelasticity With Applications to Geomechanics and Hydrogeology. Princeton University Press, Princeton, NJ.

de Wijs HJ (1951) Statistics of ore distribution: (1) Frequency distribution of assay values. Journal of the Royal Netherlands Geological and Mining Society, 13, 365-75.
Wyborn LAI (1987) The petrology and geochemistry of alteration assemblages in the Eastern Creek Volcanics, as a guide to copper and uranium mobility associated with regional metamorphism and deformation, Mount Isa, Queensland. In: Geochemistry and Mineralization of Proterozoic Volcanic Suites (eds Pharaoh TC, Beckinsale RD, Rickard D), Geological Society, London, Special Publications no. 33, 425-34.

Zhang X, Sanderson DJ (1996) Numerical modelling of the effects of fault slip on fluid flow around extensional faults. Journal of Structural Geology, 18, 109-19.

Zhang Y, Hobbs BE, Ord A, Barnicoat A, Shao C, Walshe JL, Lin G (2003) The influence of faulting on host-rock permeability, fluid flow and ore genesis of gold deposits: a theoretical 2D numerical model. Journal of Geochemical Exploration, 78, 79, 279-84.

Zhang Y, Sorjonen-Ward P, Ord A (2006) Fluid flow during deformation associated with structural closure of the Isa Superbasin at $1575 \mathrm{Ma}$ in the Central and Northern Lawn Hill Platform, Northern Australia. Economic Geology, 101, $1293-312$. 